\title{
Intramolecular Lactones of Sialic Acids
}

\author{
Paola Rota ${ }^{1, *}$ (]) Paolo La Rocca ${ }^{2}$, Pietro Allevi ${ }^{1}$, Carlo Pappone ${ }^{3,4}$ and Luigi Anastasia ${ }^{4,5, *}$ \\ 1 Department of Biomedical, Surgical and Dental Sciences, University of Milan, 20133 Milan, Italy; \\ pietro.allevi@unimi.it \\ 2 Department of Biomedical Sciences for Health, University of Milan, 20133 Milan, Italy; \\ paolo.larocca@unimi.it \\ 3 Arrhythmology Department, IRCCS Policlinico San Donato, 20097 San Donato Milanese, Milan, Italy; \\ carlo.pappone@grupposandonato.it \\ 4 Faculty of Medicine, University of Vita-Salute San Raffaele, 20132 Milan, Italy \\ 5 Laboratory of Stem Cells for Tissue Engineering, IRCCS Policlinico San Donato, 20097 San Donato Milanese, \\ Milan, Italy \\ * Correspondence: paola.rota@unimi.it (P.R.); Anastasia.luigi@hsr.it (L.A.)
}

Received: 13 October 2020; Accepted: 28 October 2020; Published: 30 October 2020

\begin{abstract}
The so-called "sialo-chemical-biology" has become an attractive research area, as an increasing number of natural products containing a sialic acid moiety have been shown to play important roles in biological, pathological, and immunological processes. The intramolecular lactones of sialic acids are a subclass from this crucial family that could have central functions in the discrimination of physiological and pathological conditions. In this review, we report an in-depth analysis of the synthetic achievements in the preparation of the intramolecular lactones of sialic acids $(1,4-, 1,7-$ and $\gamma$-lactones), in their free and/or protected form. In particular, recent advances in the synthesis of the 1,7-lactones have allowed the preparation of key sialic acid derivatives. These compounds could be used as authentic reference standards for their correct determination in biological samples, thus overcoming some of the limitations of the previous analytical procedures.
\end{abstract}

Keywords: lactone; sialic acid; biomarker; heptafluoro derivatives; tumor

\section{Introduction}

Sialic acids (Sias) are a family of nine-carbon $\alpha$-keto aldonic acids, including both the derivatives of the progenitor neuraminic acid (Neu, 5-amino-3,5-dideoxy-D-glycero-D-galacto-2-nonulosonic acid), as the $\mathrm{N}$-acetylneuraminic acid (Neu5Ac) 1 a and the $N$-glycolylneuraminic acid (Neu5Gc) $\mathbf{1 b}$, and those of the later discovered 3-deoxy-D-glycero-D-galacto-2-nonulosonic acid or 2-keto3-deoxy-D-glycero-D-galacto-nononic acid (KDN 1c), bearing a hydroxyl group in place of the amino group at the $C 5$ position (Figure 1) [1-8].

These carbohydrates possess several unique characteristics. First, they usually occupy the distal end of the glycoconjugate glycan chains to which they are attached, which is the ideal location to mediate the interaction of the cell with the external environment, including other cells and pathogens. Therefore, they play important roles in physiological, pathological, and immunological processes [1,2,4-6]. Second, Sias-containing natural compounds are often susceptible to structural biological modifications, generating a family of more than eighty distinct members [1,4,5]. Third, due to their peculiar structures, they present unique biochemical characteristics as compared to common monosaccharides $[1,3,4,7]$. Indeed, they are biosynthesized by condensation of a neutral six-carbon unit sugar with pyruvate, and they are activated in the form of CMP- Sias (i.e., 2a-c) [1,4]. 
Main sialic acids<smiles>[R1]C1C(O)C(O)CC(O)(C(=O)O)OC1C(O)CO</smiles>

1a: $R^{1}=$ NHAc; Neu5Ac

1b: $\mathrm{R}^{1}=\mathrm{NHCOCH}_{2} \mathrm{OH} ; \mathrm{Neu} 5 \mathrm{Gc}$

1c: $\mathrm{R}^{1}=\mathrm{OH} ; \mathrm{KDN}$

\section{Modified Sias linked to glycoconjugate}

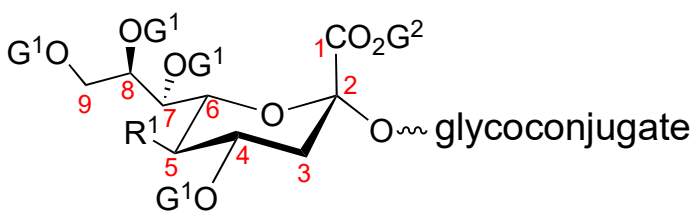

$\mathrm{G}^{1}=\mathrm{H}$, acetate, lactate, sulfate, phosphate, etc. $\mathrm{G}^{2}=\mathrm{H}, \mathrm{Me}$, etc.

$\mathrm{R}^{1}=\mathrm{NHAc}, \mathrm{NHCOCH}_{2} \mathrm{OH}, \mathrm{OH}$

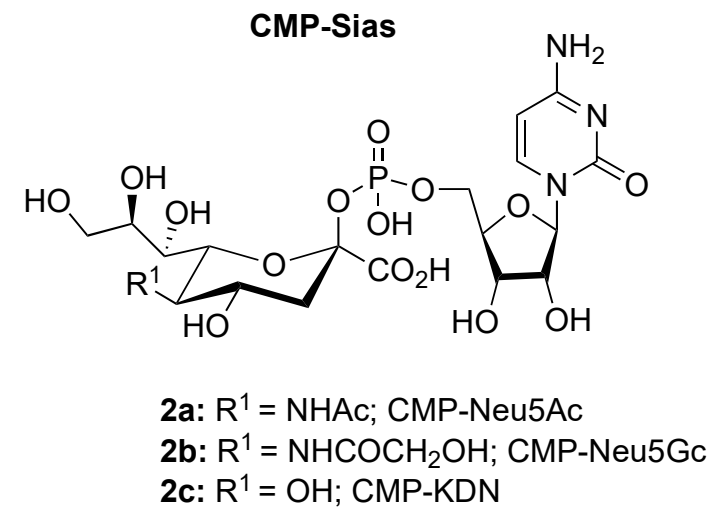

Figure 1. Representation of the three principal sialic acids (Neu5Ac 1a, Neu5Gc 1b, and KDN 1c), the general structure of modified Sias linked to the glycoconjugate chain, and the three cytidine mononucleotide Sias (CMP)-Sias (2a-c).

All the currently recognized sialic acids are biosynthetic derivatives of one of the two main family members, Neu5Ac 1a and KDN 1c (Figure 1). This is true also for the third most important derivative of the family, Neu5Gc $\mathbf{1 b}$, which is biosynthetically derived from Neu5Ac-CMP 2a through CMP-Neu5Ac hydroxylase catalysis [9-15]. The structural diversity of sialic acids is primarily generated by combinations of different substitutions at the $\mathrm{C} 5$ position or by replacement of the hydroxyl groups at the $\mathrm{C} 4, \mathrm{C} 7, \mathrm{C} 8$, and $\mathrm{C} 9$ positions with either acetate, lactate, sulfate, phosphate- or methyl-ethers (Figure 1) [1,4,7]. Moreover, other Sias derivatives, obtained by intra-lactonization of the carboxylate at $\mathrm{C} 1$ with different internal hydroxylic functions, have also been described, including compounds 3a [16] and 4a-f [17-21] (Figure 2). Furthermore, the large family of Sias also comprises a group of intramolecular 1,5-lactams, which are derived from compound 5 [22-26] and 2,3-unsaturated derivatives (2-deoxy-2,3-dehydro $\mathrm{N}$-acetylneuraminic acid, DANA 6) [27-35].

Remarkably, the lactones of Sias have been related to various pathologies, both when they are formed with other carbohydrates that precede them in the same glycan chain of glycoconjugates [36-48] and when they are formed by intramolecular lactonization [16-21]. In particular, this review will focus on the intramolecular monocycles and bicyclic lactones, clarifying the current state of the art on these molecules at the interface of chemistry and biology. Their relevance in various pathologies [49-65] has led to the synthesis and the development of an analytical technique to detect them in biological media [60]. However, we need to take into account that the recent discovery of several pitfalls [66] in the previous analytical method [60] suggests that the genuine presence of these molecules in biological matrices should be reassessed. 


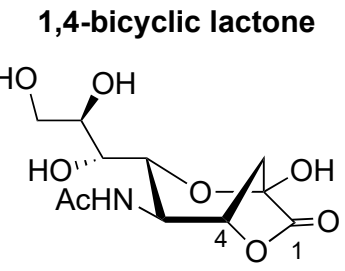

3a: Neu5Ac1,4L

\section{1,7-bicyclic lactones}

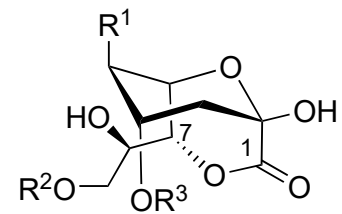

4a: $\mathrm{R}^{1}=\mathrm{NHAc}, \mathrm{R}^{2}=\mathrm{R}^{3}=\mathrm{H}$; Neu5Ac1,7L

4b: $R^{1}=N H A c, R^{2}=A c, R^{3}=H ; N e u 5,9 A c_{2} 1,7 L$

4c: $R^{1}=\mathrm{NHAc}, \mathrm{R}^{2}=\mathrm{R}^{3}=\mathrm{Ac} ; \mathrm{Neu} 4,5,9 \mathrm{Ac}_{3} 1,7 \mathrm{~L}$

4d: $\mathrm{R}^{1}=\mathrm{NHCOCH}_{2} \mathrm{OH}, \mathrm{R}^{2}=\mathrm{R}^{3}=\mathrm{H} ; \mathrm{Neu} 5 \mathrm{Gc} 1,7 \mathrm{~L}$

4e: $R^{1}=\mathrm{NHCOCH}_{2} \mathrm{OH}, \mathrm{R}^{2}=\mathrm{Ac} ; \mathrm{R}^{3}=\mathrm{H} ; \mathrm{Neu} 5 \mathrm{Gc} 9 \mathrm{Ac} 1,7 \mathrm{~L}$

4f: $\mathrm{R}^{1}=\mathrm{OH}, \mathrm{R}^{2}=\mathrm{R}^{3}=\mathrm{H}$; KDN1,7L

\section{2,3-unsaturated derivative}

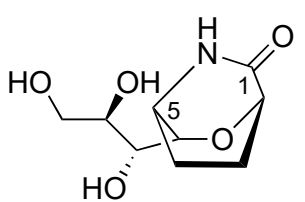

5: Neu5Ac1,5-lactam

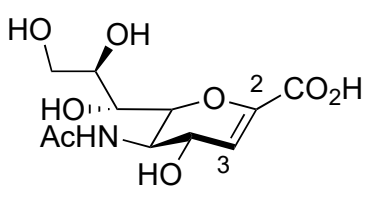

6: DANA or Neu5Ac2en

Figure 2. Representation of the 1,4-bicyclic lactone 3a, the six 1,7-bicyclic lactones $4 \mathbf{a}-\mathbf{f}$, the 1,5-bicyclic lactame 5 and the 2,3-unsaturated derivative DANA 6.

\section{Overview of the Sias Intramolecular Lactones: Synthesis and Rearrangement Mechanism}

\subsection{Synthesis of 1,4- and 1,7-bicyclic Lactones of Neu5Ac}

The first synthetic route to achieve free or protected intramolecular bicyclic lactones of Neu5Ac was published by Dereviskaya et al. in 1966 [16], affording the 1,4-bicyclic lactone 3a. The authors claimed to obtain this molecule by treating Neu5Ac 1a with $N, N^{\prime}$-dicyclohexylcarbodiimide (DCC), as a condensing agent, in pyridine followed by electrophoretic purification (Scheme 1); however, the structure of the obtained lactone was not sufficiently supported by physico-chemical data. In fact, after this initial report, the formation of this 1,4-bicyclic lactone 3a has never been observed again, nor could the compound be detected in any biological sample.

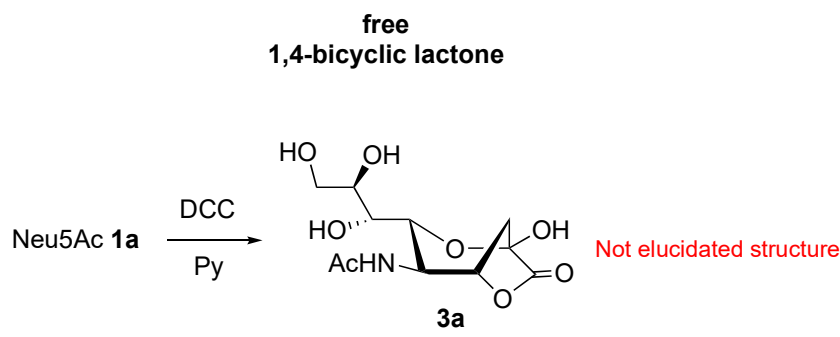

Scheme 1. Synthesis of the free 1,4-bicyclic lactone 3a starting from Neu5Ac 1a [16].

In the 1980s and 1990s, two independent research groups (Ogura's and Gervay's teams) attempted to synthesize both the intramolecular 1,4- and 1,7-bicyclic lactones, obtaining them only in their protected form [67-71]. In particular, Ogura's group reported seeding results in the synthesis, structure elucidation, as well as in the mechanism of formation of these protected bicyclic lactones [71]. Initially, they reported, almost concurrently with Kirchner et al. [72], that the peracetylation of Neu5Ac 1a also afforded, together with the desired peracetylated compound 7, the 1,7-lactone of Neu5Ac 8 as a minor by-product (Scheme 2). Its structure was previously incorrectly attributed, by Khorlin et al. [73], to the 5-acetamido- 
2,6,7,8,9-penta-O-acetyl-3,5-dideoxy-D-glycero-D-galacto-2-noneno-1,4-lactone 9, a protected monocyclic Neu5Ac 1,4-lactone, known as $\gamma$-lactone (see Section 2.3). The correct structure of the peracetylated 1,7-lactone of Neu5Ac 8 was clarified by combining nuclear magnetic resonance (NMR) analysis, mass spectrometry (MS) and X-ray crystal analysis [71,72].

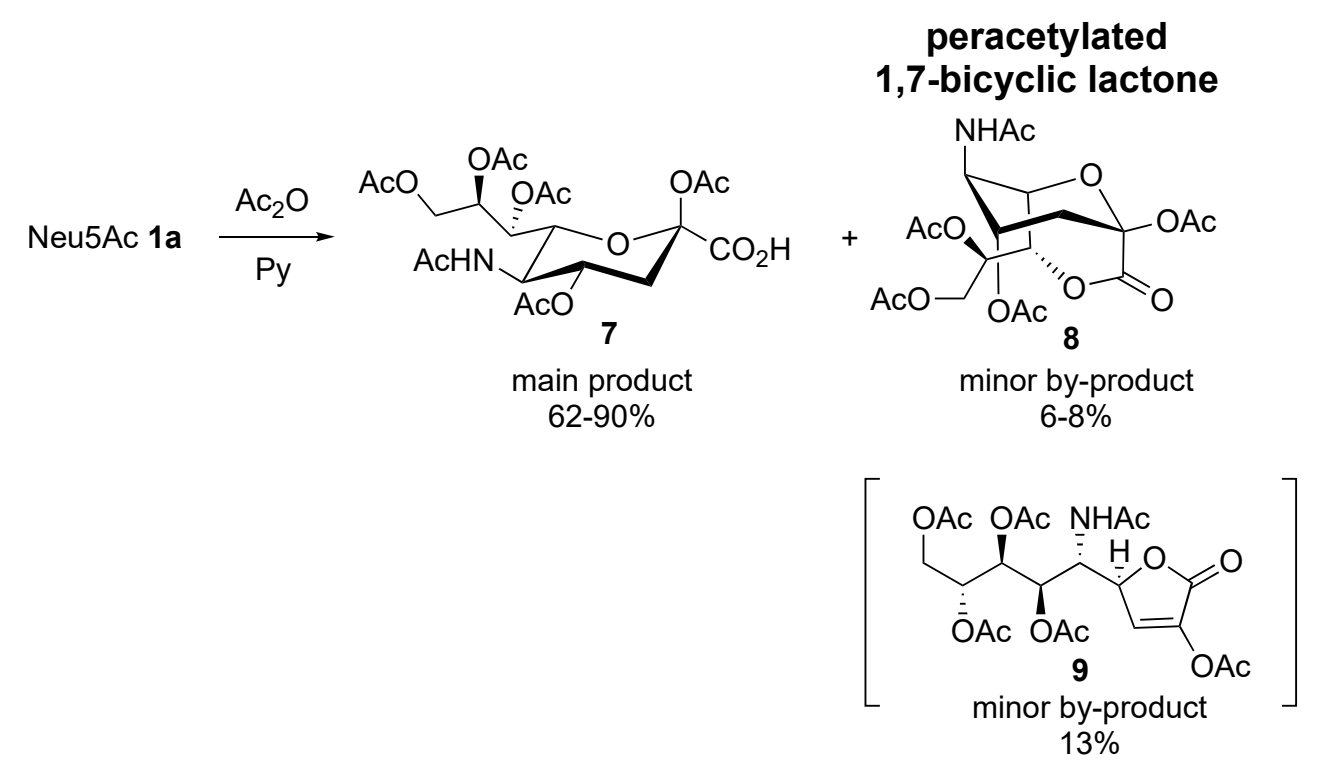

Scheme 2. Synthesis of the peracetylated 1,7-bicyclic lactone 8 as by-product of Neu5Ac 1a classical acetylation [71-73].

The peracetylated 1,7-lactone of Neu5Ac 8 was subsequently identified by Gervay's group [74] as a minor by-product ( $2 \%$ yield) during the synthesis of DANA 6 , a key precursor of many antiviral drugs. Moreover, Ogura's group reported an in-depth study on protected 1,4- and 1,7-bicyclic lactones (Scheme 3) [70]. They isolated these lactones, protected at the hydroxylic functions, by subjecting Neu5Ac 1a to acylating conditions (benzoyl chloride or benzoyl anhydride, pivaloyl chloride and ethyl chloroformate). Indeed, mixtures of compounds $\mathbf{1 0}$ and 11a-d were obtained using benzoyl agents, while compounds $\mathbf{1 2}$ and $\mathbf{1 3}$ were synthesized using ethyl chloroformate or 14a-c, using pivaloyl chloride (Scheme 3A). The correct structure of these bicyclic lactones was elucidated by ${ }^{1} \mathrm{H}-\mathrm{NMR}$ spectroscopy. Noteworthily, they proposed a fascinating mechanism of intramolecular lactonization (Scheme 3B), where a mixed anhydride on the carboxylic function is initially formed, and it is successively attacked by the 2-hydroxylic group, giving the 2-acylated derivative. Subsequently, the carboxylic function is again activated, leading to a conformational rearrangement. Therefore, the 4- or 7-hydroxylic group can promote an internal 1,4- or 1,7-lactonization; this second possibility is favored by the presence of sterically bulky substituents. Finally, the partial or total acylation of other hydroxylic functions occurs [70]. 
A

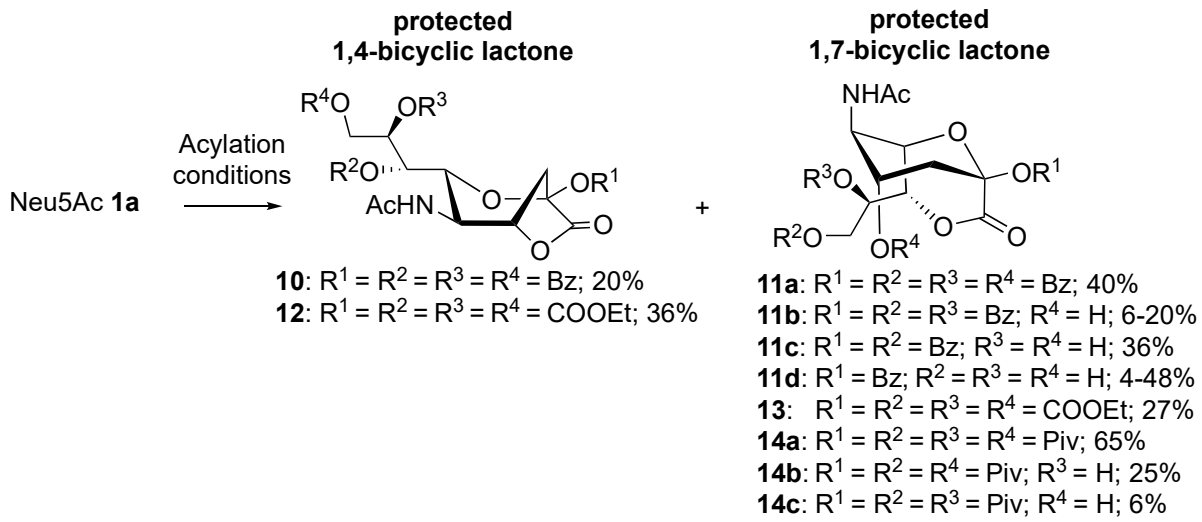

B

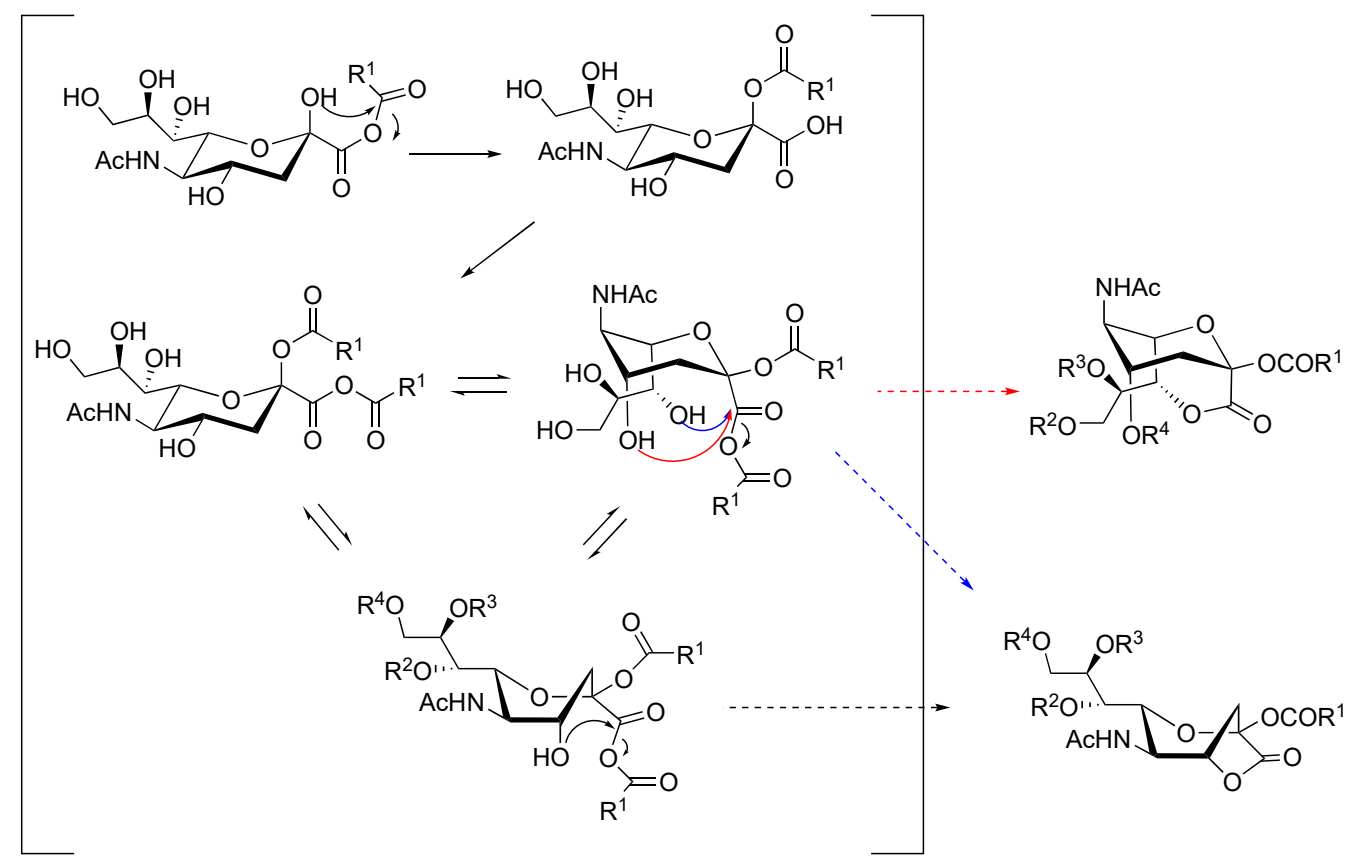

Scheme 3. (A) Synthesis of the protected 1,4-bicyclic lactones 10, 12 and the 1,7-bicyclic lactones 11a-d, 13 and 14a-c starting from Neu5Ac 1a [70]; (B) proposed mechanism of intramolecular lactonization [70].

In the 1990s, in light of Ogura's work, Gervay's group attempted the synthesis of these bicyclic lactones, but they obtained them only in the protected form (Scheme 4). In particular, they proposed [67] the use of the 1,4-protected compounds as starting material to synthesize a new class of molecules, the amino acid-NeuAc saccharopeptides (Scheme 4A). For this purpose, starting from Neu5Ac 1a, or from its 2-O-methyl derivative 15, they synthesized mixtures of 1,4- and 1,7-lactones, 10 and 11a, or 16 and 17, respectively. Then, lactones 10 and 16 were treated with protected glycine to give the desired saccharopeptides 18 or 19. Importantly, this synthetic strategy also allowed the obtainment of several sialyl donors. A second application that was proposed [68] concerned the use of protected ${ }^{13} \mathrm{C}$-labeled intramolecular 1,4 - and 1,7 -lactones, $10-{ }^{13} \mathrm{C}$ and $11 \mathrm{a}-{ }^{13} \mathrm{C}$ or $16-{ }^{13} \mathrm{C}$ and $17-{ }^{13} \mathrm{C}$, obtained from Sias $1 \mathrm{a}^{13} \mathrm{C}$ and ${ }^{15}-{ }^{13} \mathrm{C}$, respectively. They are suitable model compounds to study more complex sialyllactones by the isotope edited NMR spectroscopy technique (Scheme 4B). Notably, the authors concluded that further investigations would have been necessary to confirm the applicability of the proposed method also on the unprotected 1,4- or 1,7-lactones, as they failed to obtain them in free form. Interestingly, Gervay's group performed a computational study [69] to evaluate 
whether the sialyllactones, or their derivatives, could be a valid scaffold in the design of high-affinity neuraminidase inhibitors. For this purpose, they used virtual free 1,4- and 1,7-bicyclic lactones to compare the ability of different computational methods to reproduce the NMR constant coupling of these molecules.

A

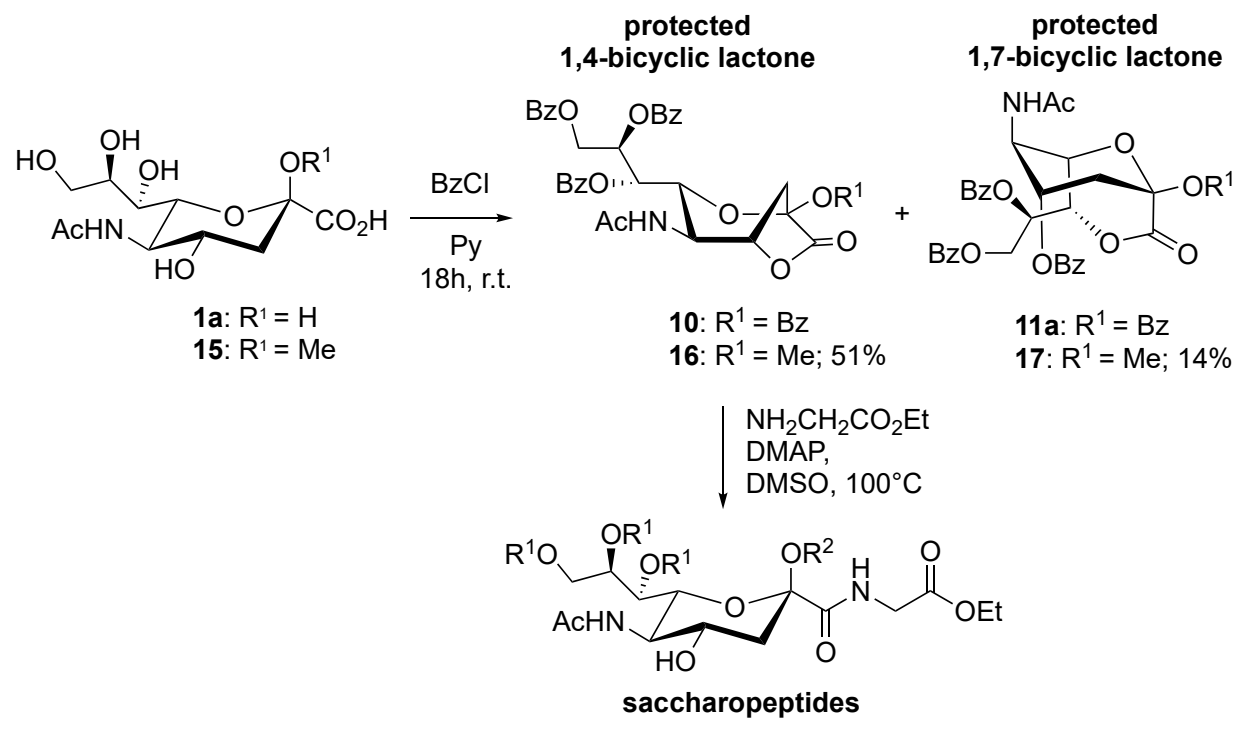

18: $R^{1}=R^{2}=B z ; 26 \%$

19: $R^{1}=B z ; R^{2}=M e ; 34 \%$

B


Scheme 4. (A) Synthesis of the saccharopeptides 18 and 19 via the protected 1,4-bicyclic lactones 10 and 16 [67]; (B) synthesis of the protected ${ }^{13} \mathrm{C}$-labeled 1,4-bicyclic lactones $10^{13} \mathrm{C}$ and $1 \mathbf{1 6}^{-13} \mathrm{C}$ and the 1,7-bicyclic lactones $11 a^{-13} \mathrm{C}$ and $17-{ }^{13} \mathrm{C}[68]$.

Richard R. Schmidt's group reported a biologically interesting study concerning the synthesis of some protected Neu5Ac 1,7-bicyclic lactones (20a-c and 21a-c; Scheme 5) [75]. They used the lactones 21a-c, as sialyl acceptors, and the phosphite 22, as a donor, for the synthesis of $\beta$-2,8-unnatural saccharides 23a-c. This synthetic strategy represented a novel and interesting approach for the preparation of unusual gangliosides starting from these 1,7-lactonic compounds. 
Protected

1,7-bicyclic lactone

$$
\begin{aligned}
& \text { 20a: } R^{1}=R^{2}=P i v ; R^{3}=R^{4}=H \\
& \text { 20b: } R^{1}=M e R^{2}=P i v ; R^{3}=R^{4}=H \\
& \text { 20c: } R^{1}=M e R^{2}=A c ; R^{3}=R^{4}=H \\
& \text { 21a: } R^{1}=R^{2}=P i v ; R^{3}=H ; R^{4}=B n \\
& \text { 21b: } R^{1}=M e R^{2}=P i v ; R^{3}=H ; R^{4}=B n \\
& \text { 21c: } R^{1}=M e R^{2}=A c ; R^{3}=H ; R^{4}=B n
\end{aligned}
$$



Scheme 5. Protected 1,7-byciclic lactones 20a-c and 21a-c and synthesis of the $\beta-2,8-$ unnatural saccharides 23a-c [75].

Overall, these seminal studies reached several important goals, as they: (i) established synthetic routes for the synthesis of protected 1,4- and 1,7- lactones, yet still in as mixtures; (ii) elucidated their correct structures, which was not obvious; (iii) clarified the molecular mechanism leading to their formation, which was also intricate; (iv) showed their application in the biological field. However, the main limit of these studies was that they all failed in delivering the free bicyclic lactones, as only the corresponding protected derivatives could be obtained. Indeed, to date, the synthesis of the free 1,4-bicyclic lactone 3a remains elusive. On the other hand, the synthesis of the free 1,7-lactones (4a, 4e, and 4f) was accomplished by Allevi's group in the 2000s [17-21,66,76], starting from Neu5Ac, Neu5Gc, and KDN, respectively (for the synthesis of 1,7-lactones of Neu5Gc and KDN, 4e and 4f, see Section 2.2). Actually, the effective idea for the synthesis of lactone $4 \mathbf{a}$ was simply the use of a bulky and easily removable acylating agent. For this purpose, Neu5Ac 1a was treated with benzyl chloroformate in a dimethylformamide-tetrahydrofuran (DMF-THF) mixture containing triethylamine, affording the 1,7-lactone 24, exclusively protected at the anomeric hydroxylic function, as reported in Scheme 6. The synthesis of the desired free $\mathrm{N}$-acetylneuraminic acid 1,7-lactone (Neu5Ac1,7L) 4a [77] was accomplished by hydrogenolysis of the benzyloxy carbonyl function of compound $\mathbf{2 4}$ in anhydrous ethyl acetate. The structure of the intermediate $\mathbf{2 4}$ was attributed by performing a complete NMR analysis and its synthetic conversion into the peracetylated derivative 25 [17]. Moreover, the low stability of this 1,7-lactone 4a, under neutral or acidic aqueous solutions, was also suggested [17-21,66,78] (see Section 3.4). Notably, in this way, they could validate the mechanism of the intramolecular lactonization, which was previously hypothesized by Ogura and co-workers [70]. 
A

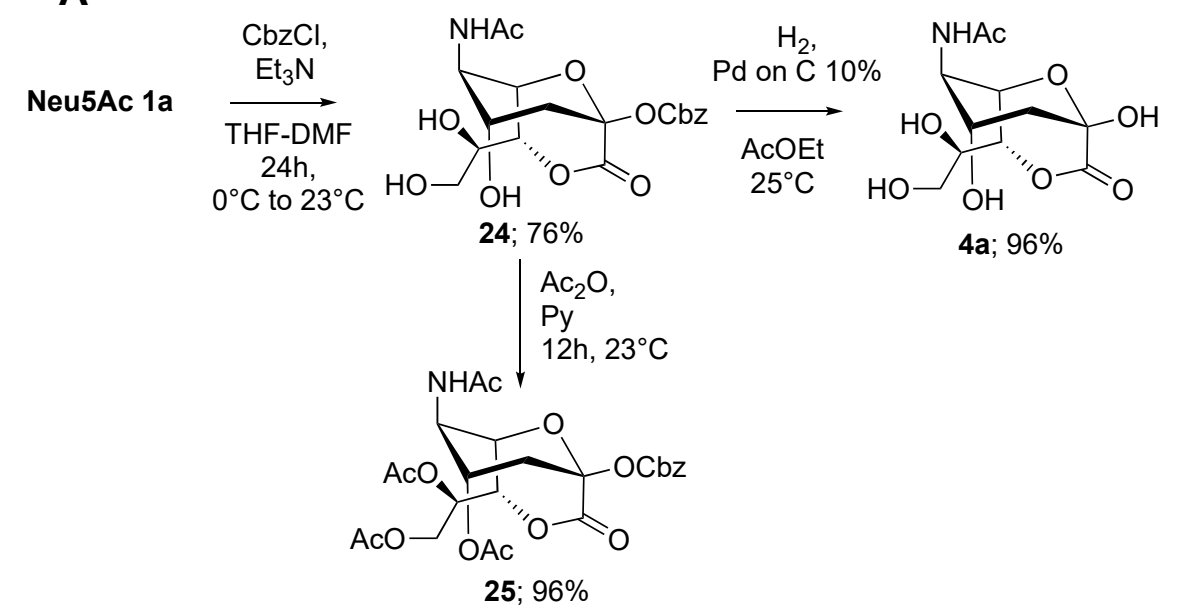

B



isotopically labeled

1,7-bicyclic lactones

$$
\begin{aligned}
& \text { 1a-d } d_{3}: R^{1}=\mathrm{NHCOCD}_{3} ; R^{2}=R^{3}=H \\
& \text { 1a-d } d_{5}: R^{1}=\mathrm{NHCOCD}_{3} ; R^{2}=R^{3}=D
\end{aligned}
$$



$$
\begin{aligned}
& \text { 4a-d } d_{3}: R^{1}=N^{2 H C O C D}{ }_{3}, R^{2}=R^{3}=H \\
& \text { 4a-d } d_{5}: R^{1}=N_{H C O C D}, R^{2}=R^{3}=D
\end{aligned}
$$

Scheme 6. (A) Synthesis of the free 1,7-bicyclic lactone of Neu5Ac 4a starting from Neu5Ac 1a [17]; (B) isotopically labeled 1,7-byciclic lactones $4 \mathbf{a}-\boldsymbol{d}_{3}$ and $\mathbf{4} \mathbf{a}-\boldsymbol{d}_{5}$ derived from the corresponding Sias $1 \mathrm{a}-d_{3}$ and $1 \mathrm{a}-d_{5}[18]$.

Furthermore, the same authors also synthesized the deuterated isotopologues of the 1,7-lactone 4a for its use as an authentic internal standard for high-performance liquid chromatography (HPLC) and GC analyses, coupled with mass spectrometry [18]. The isotopically labeled lactones $\mathbf{4 a -} \boldsymbol{d}_{3}, \mathbf{4 a -} \boldsymbol{d}_{5}$ have been synthesized, under similar reaction conditions as for $\mathbf{4 a}$, starting from the isotopically labeled Sias $1 \mathrm{a}-\boldsymbol{d}_{3}, \mathbf{1 a}-\boldsymbol{d}_{5}$, which were labeled with deuterium at the amido group alone or both at the amido-function and the C3-position.

\subsection{Synthesis of 1,4- and 1,7-bicyclic Lactones of Neu5Gc and KDN}

As we will explain shortly, the bicycle lactones of Neu5Gc $4 \mathbf{d}$ and KDN $4 \mathrm{f}$ have been less studied than those of Neu5Ac 4a. The first attempt to isolate and characterize these compounds, in a protected form, was realized by Ogura's group in 1992 [79] on the peracetylated derivative of KDN 26 (Scheme 7A). The protected lactone $\mathbf{2 6}$ was reached, as a major compound from KDN 1c, after acylation with acetic anhydride in pyridine and esterification, together with compounds $\mathbf{2 7 a}$ and $\mathbf{2 7} \mathbf{b}$. The authors clarified the structure of $\mathbf{2 6}$ using NMR and X-ray diffraction analyses. 


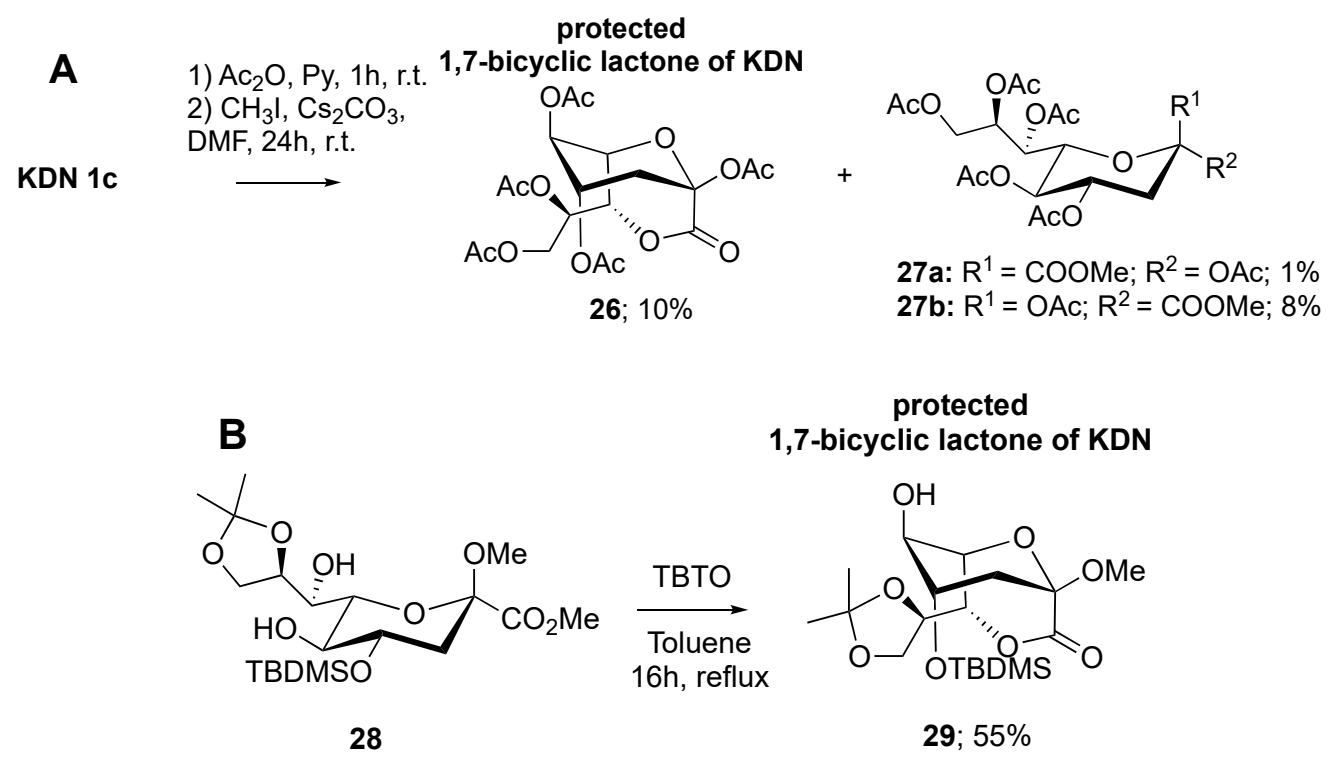

Scheme 7. (A) Synthesis of the peracetylated 1,7-bicylclic lactone of KDN 26 [79]; (B) synthesis of the protected 1,7-bicylclic lactone of KDN 29 [80].

A second work, published in 1994 by David et al. [80], described the reaction of the partially protected Neu5Ac derivative 28 with tributyltin oxide, affording the 1,7-lactone 29 in $55 \%$ yield (Scheme 7B).

These two articles remain the only sporadic attempts of achieving 1,7-protected lactones of KDN; while there are no papers on obtaining Neu5Gc lactone derivatives, before the articles published by Allevi et al. in the 2010 .

In that year, Allevi et al. [19], in light of the knowledge on Neu5Ac 4a lactone, synthesized the free 1,7-lactones of Neu5Gc $4 \mathbf{d}$ and KDN $4 \mathbf{f}$. As depicted in Scheme 8A, Neu5Gc $\mathbf{1 b}$ was transformed to the protected 1,7-lactone 30, under similar reaction conditions reported for the achievement of compound 24. Then, the hydrogenolysis of this intermediate, in anhydrous ethyl acetate, afforded the desired lactone of Neu5Gc 4d. A similar route, carried out on the KDN 1c, led to the formation of its protected 1,7-lactone 31, together with the by-product 32. Finally, the hydrogenolysis of $\mathbf{3 1}$ gave the free 1,7-bicyclic lactone 4 f.

Notably, the set-up of an accessible and versatile route to synthesize the 1,7-lactones $4 \mathbf{a}, \mathbf{4 d}$, and $\mathbf{4 f}$, in high yields, allows their use as authentic standards for analytical investigations and biological evaluations.

Moreover, the deuterated derivatives of Neu5Gc have been reported as authentic internal standards for the analysis by MS spectrometry techniques [18]. Similarly to that described above for Neu5Ac derivatives, isotopic lactones $\mathbf{4} \mathbf{d}-\boldsymbol{d}_{2}, \mathbf{4} \mathbf{d}-\boldsymbol{d}_{\mathbf{4}}$ have been accomplished starting from the isotopically labeled Sias $\mathbf{1} \mathbf{b}-\boldsymbol{d}_{\mathbf{2}}, \mathbf{1} \mathbf{b}-\boldsymbol{d}_{\mathbf{4}}$ (Scheme $8 \mathrm{~B}$ ), under analogous reaction conditions to those previously described (see Section 2.1). 
A

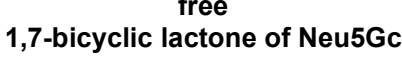
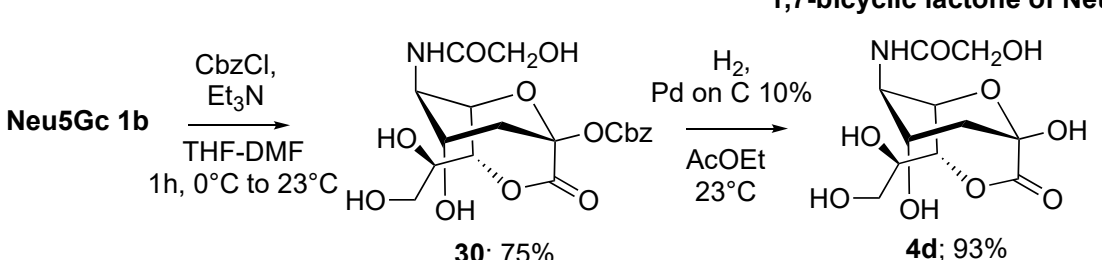

30; $75 \%$

4d; $93 \%$
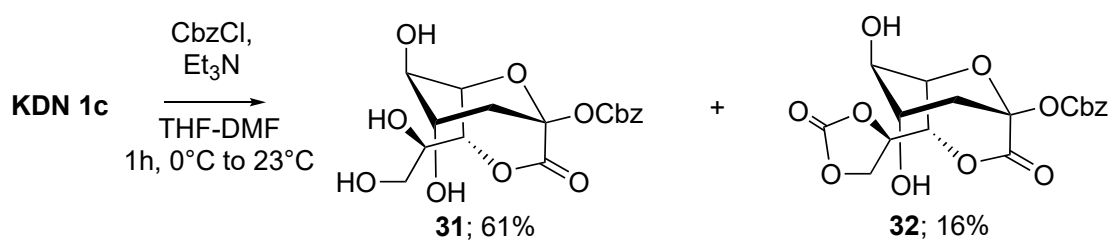

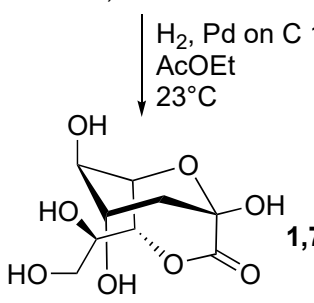

32; $16 \%$

4f; $91 \%$

B

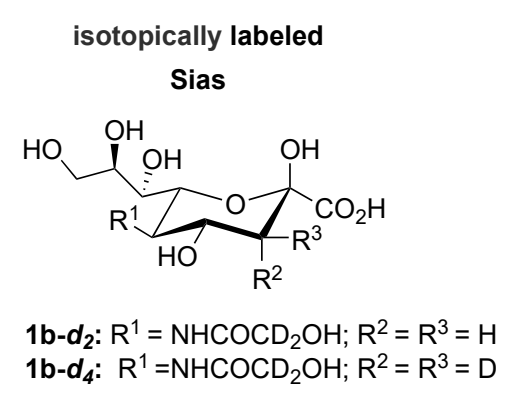

$$
\begin{aligned}
& \text { isotopically labeled } \\
& \text { 4d-d } d_{2}: \mathrm{R}^{1}=\mathrm{NHCOCD} \mathrm{R}^{1}=\mathrm{NHCOCD}, \mathrm{R}^{2}=\mathrm{R}^{3}=\mathrm{H} \\
& \text { d,7-bicyclic lactones }
\end{aligned}
$$

Scheme 8. (A) Synthesis of the free 1,7-bicyclic lactone of Neu5Gc $4 \mathbf{d}$ and of KDN 4f, starting from Neu5Gc $\mathbf{1} \mathbf{b}$ and KDN $\mathbf{1 c}$, respectively [19]; (B) isotopically labeled 1,7-byciclic lactones $\mathbf{4} \mathbf{d}-\boldsymbol{d}_{\mathbf{2}}$ and $\mathbf{4} \mathbf{d}-\boldsymbol{d}_{\mathbf{4}}$ derived from the corresponding Sias $\mathbf{1} \mathbf{b}-\boldsymbol{d}_{\mathbf{2}}$ and $\mathbf{1} \mathbf{b}-\boldsymbol{d}_{\mathbf{4}}$ [18].

\subsection{Synthesis of $\gamma$-Lactones of Sias}

The free $\gamma$-lactone of Neu5Ac 33 was initially studied only as a synthetic synthon, as it had never been detected in biological samples. However, more recently, its formation was shown during the degradation of 1,7 Sias lactones, which could be present in natural matrices [78]. Historically, the synthesis of this lactone was instrumental for the attribution of the correct Neu5Ac 1a C4 configuration [80-82] (for a complete discussion of this topic, see recent book chapter "Exploration of the Sialic Acid World" by R. Schauer and J. P. Kamerling) [1]. Moreover, other protected $\gamma$-lactones have been shown to be key intermediates in the synthesis of several natural compounds and enzymatic inhibitors.

Kuhn et al. led some pioneering studies in the field in the late 1950s and 1960s. In particular, in 1962, they proposed a synthetic route to Neu5Ac 1a via the free $\gamma$-lactone of Neu5Ac 35 (Scheme 9A), which also allowed reassessment and reassignment of its stereochemistry [83]. Briefly, the condensation of the $\mathrm{N}$-acetylmannosamine 34 and tert-butyloxaloacetate in methanol $(\mathrm{MeOH})$ yielded the 3-carboxy-t-butyl $\gamma$-lactone of Neu5Ac 35 in $48 \%$ yield. Successively, lactone 35 was decarboxylated, affording the free $\gamma$-lactone 33 , which was directly hydrolyzed in $2 \mathrm{M}$ sodium hydroxide $(\mathrm{NaOH})$ to give the pure Neu5Ac 1a (34\% yield). Comparable results were obtained starting 
from the 4,6-O-benzylidene derivative of $\mathrm{N}$-acetylglucosamine 36, giving the protected lactone 38, eventually affording lactone 33 after deprotection and decarboxylation. Finally, compound 33 was directly hydrolyzed to Neu5Ac 1a in 30\% yield (Scheme 9B).

A

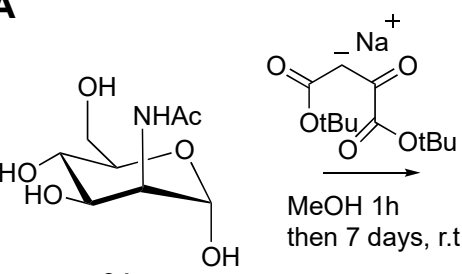

34

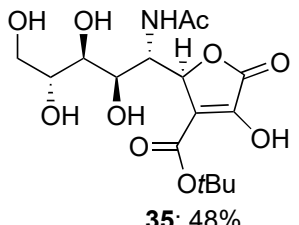

35; $48 \%$

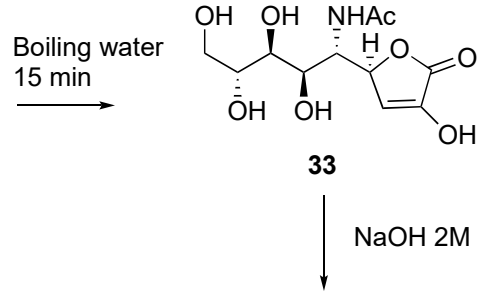

Neu5Ac 1a; $34 \%$

B



36: $\mathrm{R}=\mathrm{NHAC}$ 37: $\mathrm{R}=\mathrm{NHCOCH}_{2} \mathrm{OH}$<smiles>[R]C([C@H](O)[C@H]1O[C@H](P)OC[C@H]1O)[C@H]1OC(=O)C(O)=C1C(=O)O</smiles>

38: $\mathrm{R}=\mathrm{NHAC}$

39: $\mathrm{R}=\mathrm{NHCOCH} \mathrm{HH}_{2}$
1. $\mathrm{Pd} / \mathrm{H}_{2}$

2. Boiling water $\mathrm{OH} \quad \mathrm{OH} \quad \mathrm{R}$ $\stackrel{15 \mathrm{~min}}{\longrightarrow}$<smiles>[R]C(C1C=C(O)C(=O)O1)C(O)C(O)CO</smiles>

33: $\mathrm{R}=\mathrm{NHAC}$ 40: $\mathrm{R}=\mathrm{NHCOCH}_{2} \mathrm{OH}$ $\mathrm{NaOH} 2 \mathrm{M}$

Neu5Ac $1 \mathrm{a} ; 30 \%$ or Neu5Gc 1 b; $40 \%$

Scheme 9. (A) Synthesis of Neu5Ac 1a starting from N-acetylmannosamine 34 [83]; (B) synthesis of Neu5Ac 1a and Neu5Gc $\mathbf{1 b}$ starting from the protected compounds $\mathbf{3 6}$ and 37, respectively [83,84].

A few years later, this synthetic method was applied by Faillard for the synthesis of $\mathrm{N}$-glycolylneuraminic acid $\mathbf{1 b}$ (Neu5Gc), starting from $\mathrm{N}$-glycolylglucosamine 37 via its protected and free $\gamma$-lactones, 39 and 40, respectively [84]. The free $\gamma$-lactone 40 could be converted into the pure Neu5Gc $1 \mathbf{b}$ under basic conditions (Scheme 9B).

The free $\gamma$-lactone of Neu5Ac was obtained also by Dereviskaya [16], although without any chemical-physical properties elucidation. In fact, the complete chemical-physical characterization (NMR, MS, ect.) of this molecule was reported only several decades later, when two independent synthetic routes were published $[77,85]$, as discussed later in this review.

Between 1966 and 2010, major efforts in the field were directed to study some protected $\gamma$-lactones, as they were suitable intermediates to synthesize various Neu5Ac substituted derivatives. In those years, two independent studies by Khorlin [86] and by Holmqusit [87] are of particular interest, as they described the synthesis of several sialidase inhibitors. Successively, Zbiral and Schmid obtained the acetylated $\gamma$-lactone of Neu5Ac 41 in good yield (52\% overall yield) [88]. This $\gamma$-lactone was synthesized from compound 42, via a classical acetylation reaction to afford the intermediate 43 , followed by treatment with $\mathrm{N}$-bromosuccinimide (NBS) (Scheme 10).



$$
42
$$<smiles>CC(C)=O</smiles>

43; $90 \%$

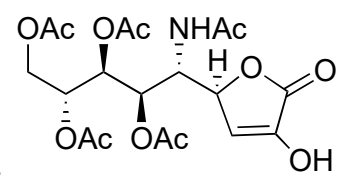

41; $58 \%$

Scheme 10. Synthesis of protected $\gamma$-lactone 41 [88]. 
Very significant results in this field were reported in the 1980s by Ogura's group [70,88], concerning the synthesis of some differently protected $\gamma$-lactones of Neu5Ac of relevant biological interest. To this purpose, Neu5Ac 1a was first dissolved in DMF and then treated with an excess of cesium carbonate $\left(\mathrm{Cs}_{2} \mathrm{CO}_{3}\right)$, together with the appropriate reagent: (i) methyl iodide, (ii) benzyl bromide and (iii) allyl bromide, respectively. After $1.5-3 \mathrm{~h}$ at $40{ }^{\circ} \mathrm{C}$, the corresponding protected lactones 44-46 where obtained in 42-78\% yield (Scheme 11A). Additionally, the methylated $\gamma$-lactone 44 could be obtained treating the methyl ester $\mathbf{4 7}$ in methanol solution with diazomethane (overnight at r.t.) in $29 \%$ yield (Scheme 11B) [70].
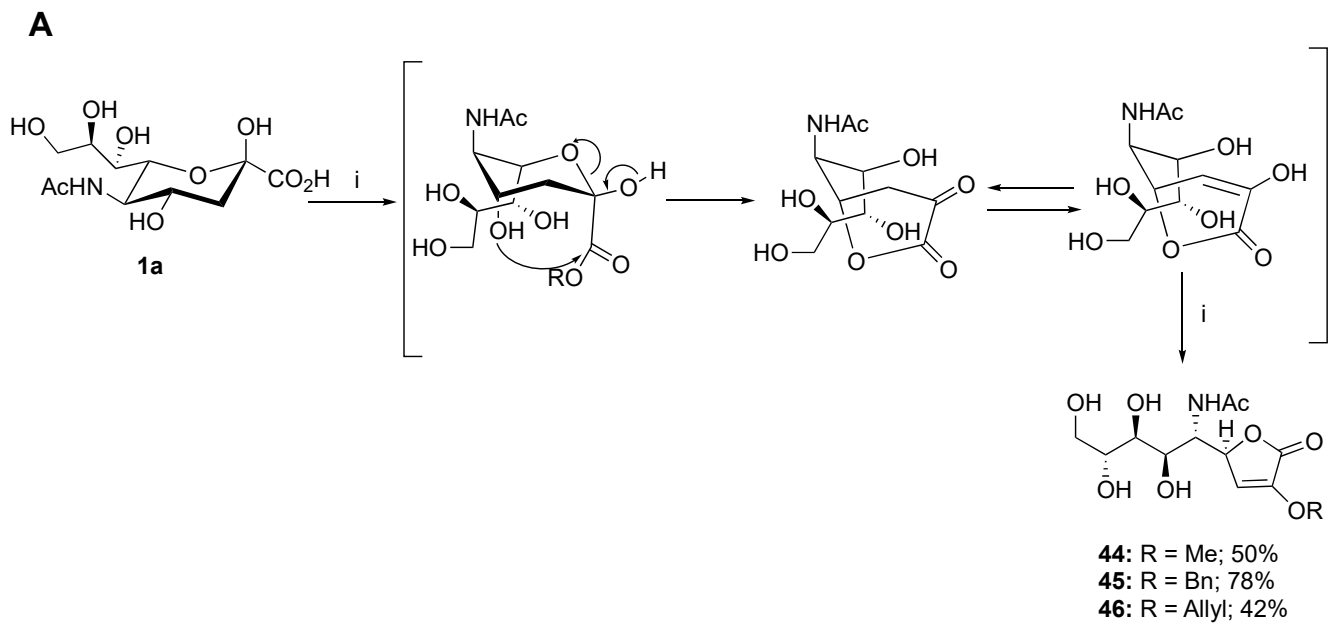

B

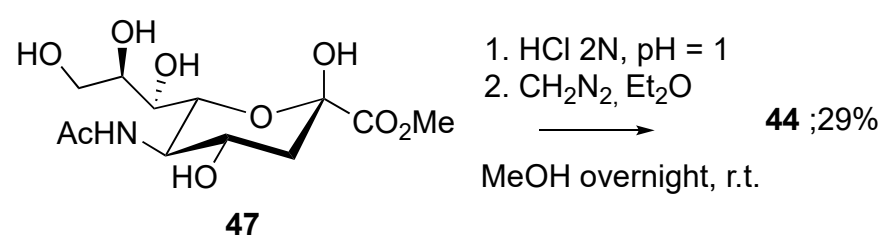

Scheme 11. (A) Synthesis of protected $\gamma$-lactones $44-46$ and the proposed reaction mechanism [89];

(B) alternative synthesis of compound 44 [70].

In the same studies, the authors hypothesized a complex mechanism for the formation of the $\gamma$-lactone, via a ${ }^{2} C_{5}$ to ${ }^{5} C_{2}$ conformation-switch, followed by an intramolecular ester exchange reaction with retention of the C4 stereochemistry (Scheme 11A) [89]. Remarkably, the proposed mechanism could only be experimentally confirmed twenty-seven years later, by Allevi's group, as described below. Surprisingly, no further studies on $\gamma$-lactones were published for over two decades, with the exception of the highly efficient synthesis of KDN 1c by Warwel in 2000 [90], which involved the free $\gamma$-lactone of KDN as key intermediate.

Only in 2010 Sawada and coworkers [85] were able to isolate the free form of the $\gamma$-lactone of Neu5Ac $33(62 \%)$, upon treatment of Neu5Ac methyl ester 47 under basic conditions using sodium methoxide ( $\mathrm{NaOMe} 0.5 \mathrm{M}$ in methanol for $0.5 \mathrm{~h}$ at $25^{\circ} \mathrm{C}$ ), followed by a neutralization and a final re-crystallization step (Scheme 12). 




Scheme 12. Synthesis of the free $\gamma$-lactone 33 starting from the methyl ester 47 [85].

Curiously, two possible intermediates (I or II) involved in the reaction mechanism were proposed: a bicyclo-1,4 lactone I or a ring-opened intermediate structure II (Scheme 12). Moreover, to confirm the correct structure, the obtained $\gamma$-lactone 33 had to be transformed into the corresponding methyl ether derivative 44 by treatment with diazomethane. More recently, in 2015, Allevi's group described a novel synthetic route to obtain the free $\gamma$-lactone 33 in very high yields (83-91\%), starting from the bicyclic 1,7-lactone $4 \mathbf{a}$ and using different acidic and basic reaction conditions in a definite reaction time [78] (Scheme 13) (for detail about reaction conditions, see Section 3.4).

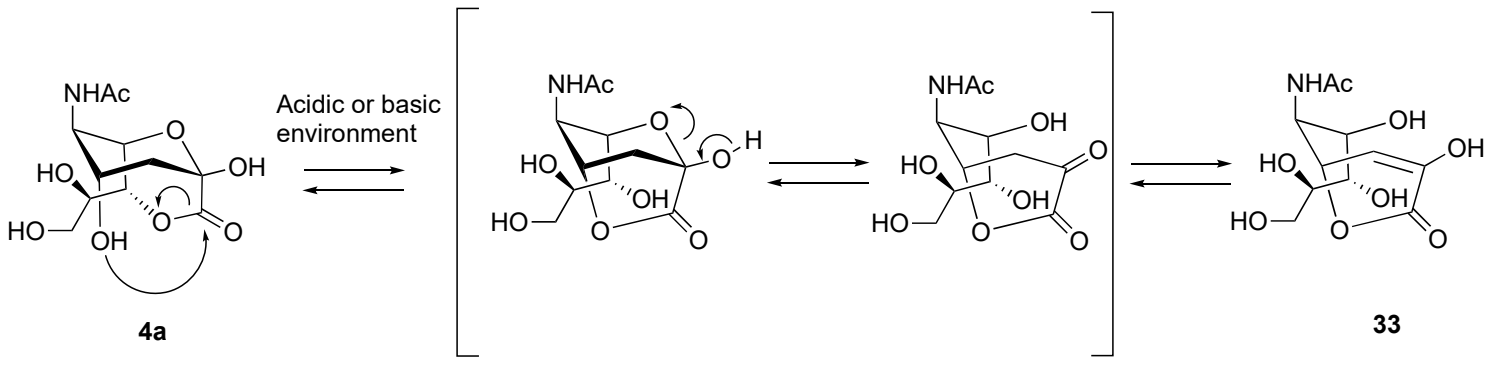

Scheme 13. Synthesis of the free $\gamma$-lactone 33 starting from the bicyclic 1,7-lactone 4a [78].

Interestingly, they discovered that the bicyclic 1,7-lactone 4a could evolve into the $\gamma$-lactone 33. These could be rationalized, taking into account the pioneering work of Ogura [89]. In particular, the formation of the $\gamma$-lactone, from different esters of Neu5Ac, goes through an intermediate flipped structure, obtained by an inversion from a ${ }^{2} \mathrm{C}_{5}$ to a ${ }^{5} \mathrm{C}_{2}$ conformation, the latter being similar to that of the 1,7-lactone. In light of this unexpected rearrangement, Allevi and coworkers proposed a possible mechanism for the formation of the $\gamma$-lactone, involving the intramolecular transesterification of the free bicyclic 1,7-lactone $4 a$, mediated by the attack of the $\mathrm{C} 4$ hydroxy group on the carboxyl function at C-1, under acidic or basic conditions (Scheme 13). According to the proposed mechanism [78], the 9-acetylated $\gamma$-lactone 48 could also easily be obtained, starting from the corresponding 1,7-lactone 4b. Conversely, the protection of the $\mathrm{C} 4$ hydroxyl group, as shown in the compound 4c, prevented the rearrangement, thus blocking the formation of the corresponding $\gamma$-lactone (Scheme 14; for detail about reaction conditions, see Section 3.4). 

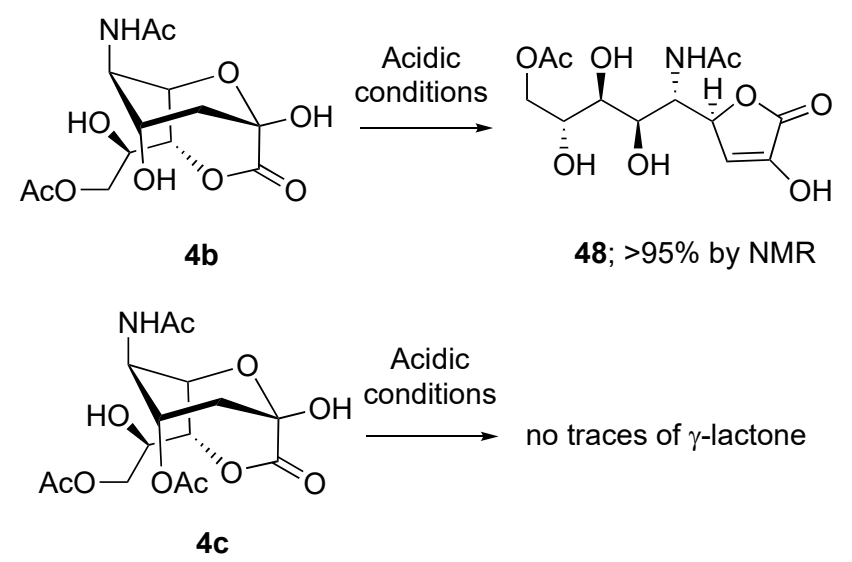

Scheme 14. Synthesis of the protected $\gamma$-lactone 48 starting from the corresponding bicyclic 1,7-lactone $4 \mathrm{~b}[78]$.

\section{Biological Relevance of Neu5ac 1,7-Lactones}

To date, the only intramolecular lactones identified in biological matrices, and related to physio-pathological states, are the 1,7-lactones of Sias 4a-e. Instead, to the best of our knowledge, 1,4- or $\gamma$-lactone derivatives have not been identified in glycoconjugates.

In this section, before reviewing the biological functions of the 1,7-lactones of Sias, we will briefly touch on the analytical method used for their identification in biological samples [60]. Indeed, these two aspects are closely related, as the identification of these molecules, which has been carried out almost exclusively with the gas chromatography-mass spectrometry (GC-MS) method developed by Zanetta and collaborators in 2001 [60], could have generated incorrect results due to some recently discovered glitches in the analytical method [66]. However, recently, the use of biochemical assays (differential scanning fluorometric, kinetic studies) performed with authentic standards of these lactones has overcome the limitations of the GC-MS method by Zanetta $[63,64]$.

\subsection{Analytical and Biochemical Techniques Applied to Identify Neu5Ac 1,7-Lactones}

The GC-MS method, reported by Zanetta et al. in 2001 [60], was used to identify several sialic acids derivatives in biological samples. The three fundamental steps of the method are depicted in Scheme 15, and consist of: (i) the release of sialic acids from the glycoconjugates; (ii) the derivatization of their carboxylic function with diazomethane and (iii) the derivatization of the hydroxyl functions with heptafluorobutyric anhydride (HFBAA) (except the semi-acetal one at C2, see Scheme 15 for details). It should be noted that the 1,7-lactones of Sias were the only subclass of compounds that could be determined without the derivatization step with diazomethane.

The main features of this method, which quickly became the preferred analytical method in the field, were: (i) the possibility to analyze different classes of compounds, including oligosaccharides, glycolipids and glycoproteins; (ii) the low interference of peptides and amino acids, which are present in the sample and that can be simultaneously analyzed with the Sias; (iii) the lack of intermediate purification steps of Sias after the initial hydrolysis; (iv) the prompt identification of the different analytes as heptafluorobutyrate (HFB) derivatives using their specific ions in the MS profile; (v) the stability of the HFB derivatives. 


\section{Sias-Glycoconjugates}

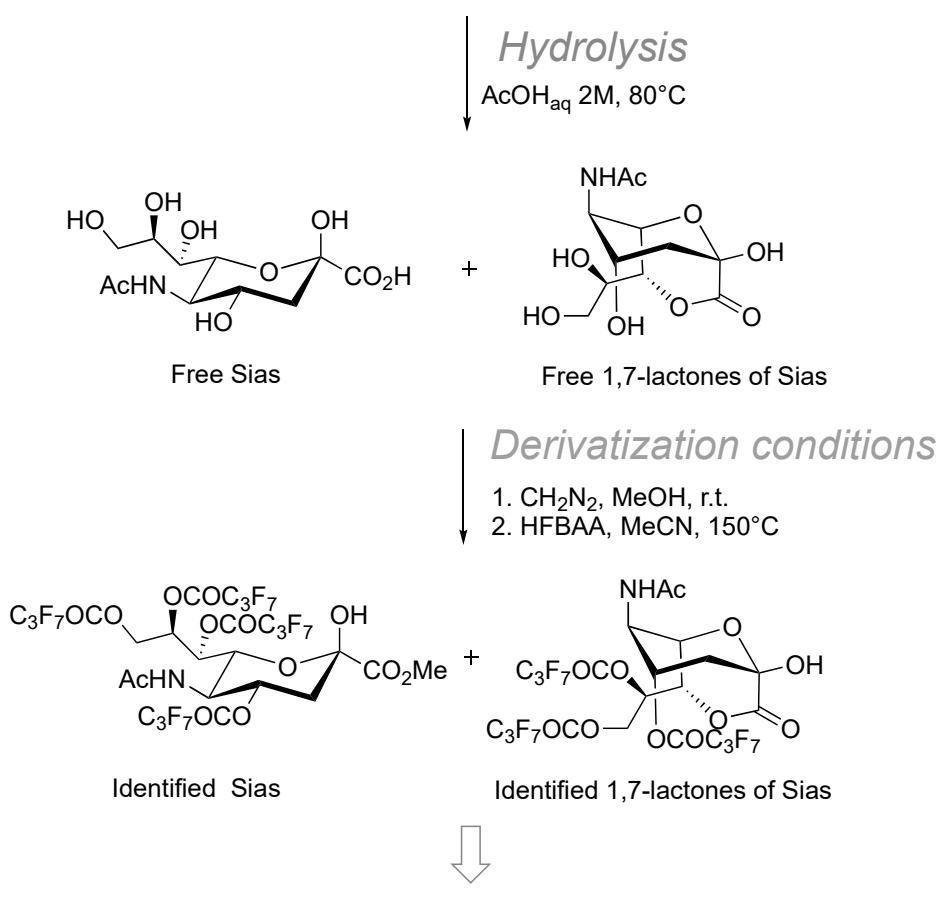

\section{GC-MS analysis}

Scheme 15. The three fundamental steps of Zanetta's gas chromatography-mass spectrometry (GC-MS) method. From the hydrolysis of the glycoconjugates with acetic acid $(\mathrm{AcOH})$, different Sias and their lactones are produced. Here, by way of example, the structures of Neu5Ac 1a and its lactone 4a have been reported [60].

However, a critical pitfall of the analytical method was overlooked for almost two decades [60]. In fact, due to the lack of authentic reference samples for most Sias, including the 1,7-lactones, their structure was established only by the mass fragmentation profile, after a required multistep isolation and derivatization process that could alter their original structure. Indeed, it was recently shown [66] that the 1,7-bicyclic lactones, including the three derivatives of $\mathrm{N}$-acetylneuraminic acid $\mathbf{4 a - c}$ and the two derivatives of $\mathrm{N}$-glycolylneuraminic $\mathbf{4 d - e}$, cannot be determined using the current analytical methodology (see Section 3.4) [60].

The GC-MS method of Zanetta et al. was also used in a study investigating the physiological role played by the 1,7-lactones in the interleukin-4 (IL-4) signaling modulation [59]. In particular, the authors combined the GC-MS approach with more traditional biochemical techniques, including the use of glycoconjugates immobilization methods coupled with electrophoresis, blotting techniques, and enzymatic inhibition assays using specific oligosaccharides.

\subsection{1,7-Lactones of Sias in Biological Samples}

The GC-MS analyses performed by Zanetta et al.'s method revealed the presence of 1,7-lactones in mucins of different physiological and pathological tissues from different species.

\subsubsection{Animal Tissues}

The 1,7-lactones of Sias have been initially detected in mucins of different animal species, such as in the bovine (1\%) and ovine $(0.5 \%)$ submandibular glands, in eggs of $B$. bufo, and in the skin of $A$. Anguilla. Among them, the mucins of $B$. bufo eggs were very rich in these lactones, containing all the known compounds $4 \mathbf{a}-\mathbf{e}$, where the derivative $4 \mathbf{a}$ was the most abundant [60]. 
Successively, the 1,7-lactone 4a was detected in mouse tissues in a study aimed at evaluating the distribution of the different sialic acids as endogenous substrates of coronavirus hemagglutinin-esterases [50]. In particular, the authors evaluated the distribution of 13 sialic acids, including lactone $\mathbf{4 a}$, linked to glycoproteins and glycolipids at different stages of mouse brain development. They found that the 1,7-lactone 4 a was not expressed in glycoproteins of mouse embryonic tissues nor in the newborn or the adult mouse brain. On the other hand, they found modest quantities $(0.35 \%$ of total Sias) of $4 \mathbf{a}$ in seven-day-old mice. Additionally, they found that, among the extracerebral tissues, only the liver contained this lactone (3.54\% of total Sias). In this study, the 1,7 lactone 4a was only found in the initial embryonic state (on the thirteenth day), then it could not be detected until the mouse birth. Then, at seven days from birth, it was widely expressed ( $57.73 \%$ of total Sias), although its content was reduced to minor quantities $(0.20 \%$ of total Sias) in the adult mouse. Curiously, a high concentration of this lactone was detected in the metencephalon of adult mouse tissue; on the other hand, it was absent in other cerebral or extracerebral compartments. Unfortunately, the biological significance of the occurrence of Neu5Ac1,7L in large quantities in the brain and in the liver is still puzzling to date [50].

\subsubsection{Human Healthy and Diseased Tissues}

The physiological presence of the 1,7-lactone $4 \mathbf{a}$ and its interaction with interleukin 4 (IL-4) in human tissues was investigated, suggesting the possible clinical use of this Neu5Ac derivative as a potential modulator of IL-4-mediated immune response. More specifically, in 2001, Zanetta's group disclosed that the 1,7-lactone $\mathbf{4 a}$ was the ligand of human interleukin 4 [56,58,59], thus proposing a "lectin" activity of IL-4. In fact, they found that this interleukin could bind to the mucins, extracted from B. bufo eggs, which are glycoproteins enriched in sialylated 1,7-lactones. Moreover, the authors excluded that the 1,7-lactone of Neu5Gc could be the ligand of IL-4 in the B. bufo mucins, as they performed analogous experiments on the mucins of the ovine submandibular gland, where this lactone is known to be absent [60]. Importantly, the 1,7-lactone 4a could modulate the signal transduction events initiated by IL-4 via a $63 \mathrm{kDa}$ protein (p63) on resting lymphocytes, supporting that the pathway depends on the lectin activity. Overall, the study suggests that specific carbohydrates, such as the 1,7-lactones of Sias, could be instrumental to modulate the immune system, as an alternative to therapies employing antibodies against interleukins or interleukin receptors. In fact, the involvement of the 1,7-lactone 4a in immunomodulation has been also supported by some studies performed on human purified glycoproteins from pregnant women [53]. Specifically, this molecule is highly expressed in both the mucin MUC2, having a high degree of $O$-linked glycans, and the uromodulin, holding essentially $N$-linked ones. Interestingly, the 1,7-lactone 4 a accounted for $7.7 \%$ and $35 \%$ of the overall sialic acids present in MUC2 and in the uromodulin protein, respectively. Indeed, the urine glycoproteins of pregnant women are known to specifically bind IL-4 in a Sias carbohydrate-dependent way, although the actual ligand(s) have yet to be identified [56,58,59]. Thus, these results [53] seem to support that lactone 4 a could be the ligand of IL-4, although further studies to confirm this hypothesis are still needed.

The different expression of 1,7-lactone in pathological and healthy human tissues gave a particular relevance to this molecule, suggesting its possible role as a biomarker. For example, a high amount of 1,7-Neu5Ac lactone $4 \mathbf{a}$ has been detected in glycoproteins derived from the human colon-rectum tissues, supporting its use as a possible biomarker of colon cancer, if overexpressed in pathological tissues [53]. Moreover, the presence of Neu5ac1,7L in mucins and oligosaccharides isolated from the human gut has also been reported [55]. The study underlined the difference in glycosylation of distinctive parts of the intestine. Consistent levels of lactone $4 a$ were found in different gut compartments, the highest being found in the ileum $(20-21 \%$ of total sialic acids in each sample) and in the rectum (19-26\%), whereas minor quantities were detected in the cecum (11-20\%), in the transverse (8-14\%), and in the sigmoid (6-9\%). 
Interestingly, the GC-MS analytical method of Zanetta et al. was applied to evaluate human erythrocyte membrane glycoprotein- and glycolipid-containing sialic acids of different serotypes [54]. Remarkably, these lactones were absent from the red blood cell (RBC) samples of healthy people, but were present, sometimes even at a high level, in several malignant tumors. In 2007, the Neu5Ac 1,7-lactone $4 \mathbf{a}$ was found in the erythrocyte membranes of patients affected by polycythemia vera [49]. In particular, a drastic reduction in the Sias diversity was observed, as well as the absence of Neu5Gc and its derivatives. Despite that, the 1,7-lactone 4a became a predominant compound, suggesting a crucial role of this molecule to discriminate between healthy and diseased RBC samples. Furthermore, in a study on malignant melanocytes [65], lactone 4a was found as a minor component in healthy tissues, but the dominant Sia in some malignant cells. Specifically, it was found that the Sia of monosialodihexosylganglioside (GM3) is mainly in the form of the internal 1,7-lactone $4 \mathbf{a}$. Based on the known interaction between IL-4 and 1,7-lactone, the authors proposed that the high expression of GM3 in malignant melanocytes was instrumental to "disturb" the activity of the immune system near the tumors [65].

\subsection{Recent Insights into the Biological Role of Neu5Ac 1,7-Lactone}

The biological role of $4 \mathbf{a}$ has been recently investigated in the colonization of the human intestine by commensal bacteria, such as E. coli $[63,64]$. In fact, these 1,7-lactones are relatively common in the large intestine, supporting the role of this molecule as an essential source of bacterial nutrition. In this regard, a recent work by Horne et al. [63] investigated the role of the E. coli YjhC enzyme, and its involvement in sialic acid catabolism. Notably, differential scanning fluorimetry experiments, coupled with Phenotype MicroArray, revealed that $N$-acetylneuraminic acid 1a and its 1,7-lactone 4a, along with reduced nicotinamide adenine dinucleotide (NADH), could be the biologically relevant substrates of YjhC. Notably, the 1,7-lactone 4a was selected as a model compound for in silico docking experiments, based on the obtained crystal structure of YjhC, to support the binding of this molecule in the enzyme catalytic pocket.

\subsection{Stability of the Lactones of Biological Interest and Questioning on the Real Presence of 1,7-Lactones of Sias in Biological Tissues}

As outlined in this review, the 1,7-lactones of Neu5Ac and Neu5Gc have been shown to play important roles both physiologically and pathologically. However, the relative stability of these compounds is a key feature that needs to be addressed, especially when assessing them in biological samples using multi-step extraction and purification procedures. In this regard, during their synthesis in free form (see Sections 2.1 and 2.2) [17-21,66,78], Allevi's group clarified significant features regarding the stability of these molecules. In particular, lactone $4 \mathbf{a}$ was found to be unstable in protic solvents, such as methanol and water, eventually affording the corresponding Neu5Ac methyl ester or the free Neu5Ac $[66,78]$. The same authors also elucidated the behavior of these molecules in different acidic and basic environments. In particular, treatment with a strong acidic resin (for $1 \mathrm{~h}$ at r.t.) led to the formation of the $\gamma$-lactone 33, which was transformed in free Neu5Ac 1a, after some additional time (i.e., $120 \mathrm{~h}$ at $25^{\circ} \mathrm{C}$ or $8 \mathrm{~h}$ at $80^{\circ} \mathrm{C}-$ Scheme 16 and Table 1, entries 1-2). Analogous results were obtained after treatment with hydrochloric acid ( $\mathrm{HCl}) 1 \mathrm{M}$ for $1 \mathrm{~h}$ at $80^{\circ} \mathrm{C}$ of (Entry 3). Alternatively, treatment of $4 \mathbf{a}$ for $24 \mathrm{~h}$ at RT with a weak acid, such as $\mathrm{AcOH} 2 \mathrm{M}$, led to the complete transformation into the $\gamma$-lactone 33 (Entry 4). A similar behavior was observed when the stability of $4 \mathbf{a}$ was tested under basic conditions. In particular, treatment with $\mathrm{NaOMe}$ for $30 \mathrm{~min}$ at $30{ }^{\circ} \mathrm{C}$ led to the formation of the $\gamma$-lactone 33 in very high yields (92\%, entry 6). Similarly, the use of 1,1,3,3-tetramethylguanidine (TMG) $0.05 \mathrm{M}$ at $25^{\circ} \mathrm{C}$ for 9 min afforded the same compound, which was quantitatively transformed into Neu5Ac (Entry 7 and 8), after an additional time of $72 \mathrm{~h}$ at $25^{\circ} \mathrm{C}$ (or $3 \mathrm{~h}$ at $60^{\circ} \mathrm{C}$ ). 


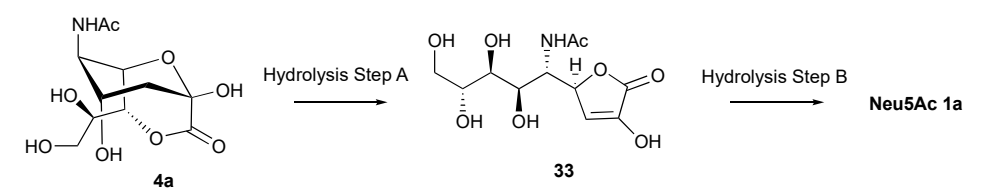

Scheme 16. General two-steps hydrolysis of compound 4a (see Table 1 for reaction conditions) [78].

Table 1. Hydrolysis reaction conditions of compound 4a (Step A) and compound 33 (Step B) [78].

\begin{tabular}{|c|c|c|c|c|c|c|}
\hline \multirow{2}{*}{ Entry } & \multirow{2}{*}{ Reagent } & \multirow{2}{*}{$\mathrm{T}\left({ }^{\circ} \mathrm{C}\right)$} & \multicolumn{2}{|r|}{ Step A } & \multicolumn{2}{|r|}{ Step B } \\
\hline & & & $t(h)$ & Yield (\%) of 33 & $t(h)$ & Yield (\%) of $1 a$ \\
\hline entry 1 & Dowex $\mathrm{H}^{+\mathrm{a}}$ & 25 & 1 & 86 & 120 & 87 \\
\hline entry 2 & Dowex $\mathrm{H}^{+\mathrm{a}}$ & 80 & - & - & 8 & 81 \\
\hline entry 3 & $1 \mathrm{M} \mathrm{HCl}^{\mathrm{a}}$ & 80 & - & - & 1 & 65 \\
\hline entry 4 & $2 \mathrm{M} \mathrm{AcOH}^{\mathrm{a}}$ & 25 & 24 & 83 & - & - \\
\hline entry 5 & $2 \mathrm{M} \mathrm{AcOH}^{\mathrm{a}}$ & 80 & 0.25 & 78 & 3 & 50 \\
\hline entry 6 & $0.5 \mathrm{M} \mathrm{NaOMe}{ }^{b}$ & 30 & 0.5 & 92 & - & - \\
\hline entry 7 & $0.05 \mathrm{M} \mathrm{TMG}^{\mathrm{b}}$ & 25 & 0.15 & 91 & 72 & 78 \\
\hline entry 8 & $0.05 \mathrm{M} \mathrm{TMG}^{\mathrm{b}}$ & 60 & - & - & 3 & 97 \\
\hline
\end{tabular}

${ }^{\mathrm{a}}$ solvent $\mathrm{H}_{2} \mathrm{O}^{\mathrm{b}}$ solvent $\mathrm{MeOH}$.

Surprisingly, when the authors investigated the standard hydrolytic conditions used to cleave Sias derivatives from glycoconjugates [60], they found that treatment of $4 \mathbf{a}$ with $\mathrm{AcOH} 2 \mathrm{M}$ at $80^{\circ} \mathrm{C}$ for 15 min yielded exclusively the $\gamma$-lactone 33 (entry 5 and Scheme 17), which eventually evolved in Neu5Ac 1a after an additional time of $3 \mathrm{~h}$. Similarly, the C9 monoacetylated 1,7-lactone $4 \mathbf{b}$, after $30 \mathrm{~min}$ at $80^{\circ} \mathrm{C}$ in $\mathrm{AcOH} 2 \mathrm{M}$, rapidly evolved in the corresponding $\gamma$-lactone 48 ( $>95 \%$ yield, quantification by NMR) [78]. On the other hand, the C4, C9 diacetylated 1,7-lactone 4c was stable under these conditions and, only after $105 \mathrm{~min}$, a partial degradation occurred, which was accompanied by the formation of the sialic acid derivative 49 (around 30\% yield, quantification by NMR) (Scheme 17).

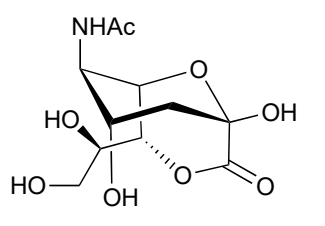

$4 a$



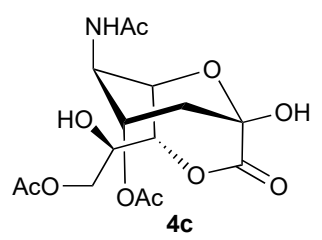

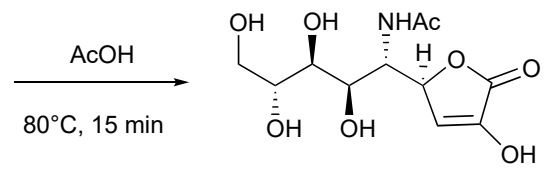

$33 ; 78 \%$<smiles>CC(Br)(Br)CCCCC(=O)O</smiles><smiles>O=C(O)CCC(=O)O</smiles>

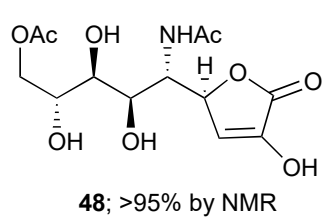

48; $>95 \%$ by NMR

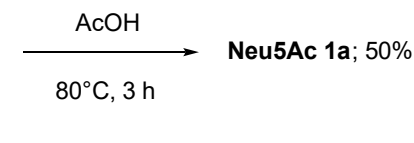
${ }^{\circ} \mathrm{C}, 3 \mathrm{~h}$ 
Overall, these results support that these 1,7-lactones could not survive under the acidic hydrolysis conditions required for their cleavage from glycoconjugates in Zanetta's method [60], calling for a complete reevaluation of their presence in biological samples and of their physiological and pathological roles.

Moreover, in the same article, Allevi's group clarified some critical flaws of the GC-MS analytical protocol used to detect Sias, including the 1,7-lactonized derivatives, as heptafluorobutyrates [66]. Performing GC-MS and NMR analyses, using the authentic reference standards of free Sias (Neu5Ac 1a; 9-acetyl Neu5Ac 50; and the 4,9-diacetyl Neu5Ac 49 derivatives) and their 1,7-lactonized analogues $(\mathbf{4 a}, \mathbf{4 b}$ and $\mathbf{4 c})$, they discovered interesting features of these compounds (Scheme 18).

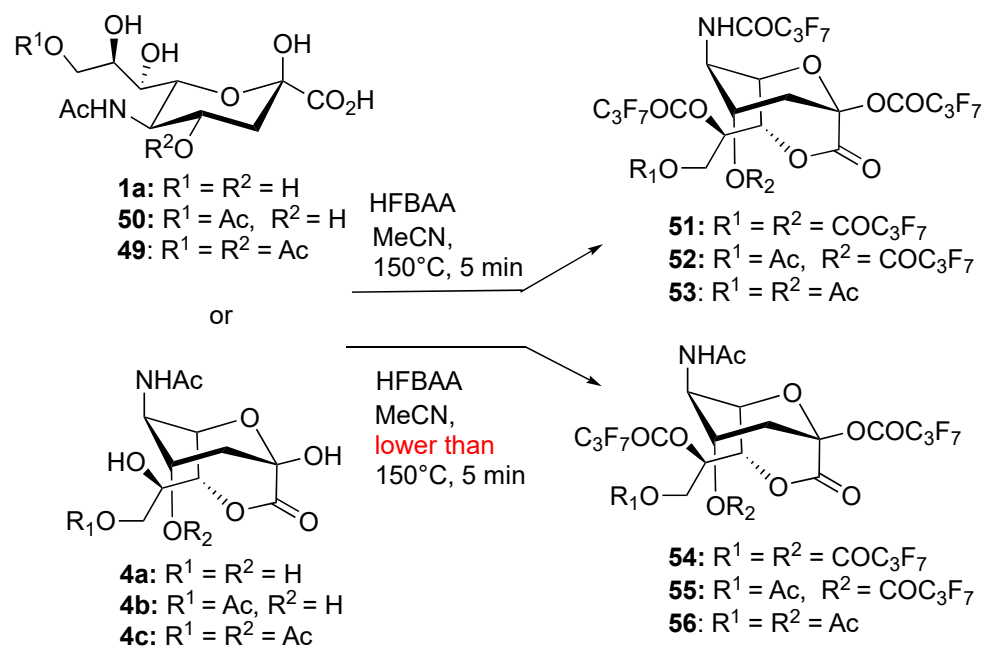

Scheme 18. Derivatization conditions with HFBAA explored by Allevi's group [66].

In particular, they demonstrated [66] that, under the reported conditions, all the sialic acid derivatives had been converted to 1,7-lactonized $\mathrm{N}$ - and $\mathrm{O}$-heptafluorobutyrates compounds, and not the expected methyl esters. Indeed, treating Sias $(\mathbf{1 a} ; \mathbf{4 9} ; \mathbf{5 0})$ or their 1,7-lactones $(\mathbf{4 a} ; \mathbf{4 b} ; \mathbf{4 c})$ with this heptafluorobutyric anhydride in $\mathrm{MeCN}$ for $5 \mathrm{~min}$ at $150^{\circ} \mathrm{C}$ (the derivatization conditions commonly used in literature [60]), only the $\mathrm{N}$-transacylated [91-94] heptafluorobutyric lactones 51-53 were obtained. Moreover, they established that the correct structures of the supposed 1,7-lactones present in the physiological media, and overexpressed in different pathologies, are those of lactones 54-56. Indeed, compounds 54-56, formed by incorrect derivatization (low temperature or low reaction times), showed the same MS fragmentation profiles previously found for 1,7-lactones by Zanetta's GC-MS method [49-56,59,65].

Overall, they substantiated that 1,7-lactones of Sias, if present in biological samples, decompose under the acidic hydrolysis conditions used for their cleavage and they are accidentally generated as unexpected artifacts during the derivatizing step from their homologs acids [66].

\section{Conclusions and Future Perspectives}

As detailed in this review, the internal lactones of sialic acids play a central role in many physiological and pathological processes. However, recent advances in understanding their reactivity and stability have also exposed the limits of their identification and quantification from biological samples [66]. Clearly, milder hydrolytic strategies are needed to remove Sias from glycoconjugates and overcome the lability of 1,7-lactone derivatives in free form. This, together with the recent advances in the synthesis of authentic standard samples, could allow the development of new analytical methods to confirm their presence in biological matrices, eventually reassessing their physiological and pathological roles. 
Funding: This work was partially supported by Ricerca Corrente funding from the Italian Ministry of Health to IRCCS Policlinico San Donato.

Acknowledgments: This review is dedicated to the memory of our mentor, Emeritus Mario Anastasia, who devoted his life to research and teaching with unmatched love and passion. We gratefully acknowledge Irene Delcarro for her skilled technical assistance.

Conflicts of Interest: The authors declare no conflict of interest.

\section{Abbreviations}

\begin{tabular}{|c|c|}
\hline $\mathrm{AcOH}$ & Acetic acid \\
\hline CMP & Cytidine mononucleotide \\
\hline $\mathrm{Cs}_{2} \mathrm{CO}_{3}$ & Cesium carbonate \\
\hline DANA & 2-Deoxy-2,3-dehydro $N$-acetylneuraminic acid \\
\hline DCC & $N, N^{\prime}$-dicyclohexylcarbodiimide \\
\hline DMF & Dimethylformamide \\
\hline GC & Gas chromatography \\
\hline GC-MS & Gas chromatography-mass spectrometry \\
\hline $\mathrm{GM}_{3}$ & Monosialodihexosylganglioside \\
\hline $\mathrm{HCl}$ & Hydrochloric acid \\
\hline HFB & Heptafluorobutyrate \\
\hline HFBAA & heptafluorobutyric anhydride \\
\hline HPLC & High-performance liquid chromatography \\
\hline IL-4 & Interleukin 4 \\
\hline $\mathrm{kDa}$ & Kilodalton \\
\hline $\mathrm{KDN}$ & $\begin{array}{l}\text { 3-Deoxy-D-glycero-D-galacto-2-nonulosonic acid or 2-keto-3-deoxy-D-glycero-D- } \\
\text { galacto-nononic acid }\end{array}$ \\
\hline $\mathrm{MeCN}$ & Acetonitrile \\
\hline $\mathrm{MeOH}$ & Methanol \\
\hline MS & Mass spectrometry \\
\hline $\mathrm{NADH}$ & Nicotinamide adenine dinucleotide, reduced \\
\hline $\mathrm{NaOH}$ & Sodium hydroxide \\
\hline $\mathrm{NaOMe}$ & Sodium methoxide \\
\hline NBS & $N$-Bromosuccinimide \\
\hline Neu & 5-Amino-3,5-dideoxy-D-glycero-D-galacto-2-nonulosonic acid or Neuraminic acid \\
\hline Neu5Ac & $N$-acetylneuraminic acid \\
\hline Neu5Ac1,7L & $N$-acetylneuraminic acid 1,7-lactone \\
\hline Neu5Gc & $N$-glycolylneuraminic acid \\
\hline NMR & Nuclear magnetic resonance \\
\hline RBC & Red blood cell \\
\hline Sias & Sialic acids \\
\hline THF & Tetrahydrofuran \\
\hline TMG & 1,1,3,3-Tetramethylguanidine \\
\hline
\end{tabular}

\section{References}

1. Schauer, R.; Kamerling, J.P. Exploration of the sialic acid world. Adv. Carbohydr. Chem. Biochem. 2018, 75, 1-213. [CrossRef] [PubMed]

2. Schauer, R. Sialic acids as regulators of molecular and cellular interactions. Curr. Opin. Struct. Biol. 2009, 19, 507-514. [CrossRef] [PubMed]

3. Schauer, R. Sialic acids: Fascinating sugars in higher animals and man. Zoology 2004, 107, 49-64. [CrossRef] [PubMed]

4. Varki, A.; Cummings, R.D.; Esko, J.D.; Stanley, P.; Hart, G.W.; Aebi, M.; Darvill, A.G.; Kinoshita, T.; Packer, N.H.; Prestegard, J.H.; et al. Essentials of Glycobiology, 3rd ed.; Cold Spring Harbor Laboratory Press: Cold Spring Harbor, NY, USA, 2015. 
5. Angata, T.; Varki, A. Chemical diversity in the sialic acids and related alpha-keto acids: An evolutionary perspective. Chem. Rev. 2002, 102, 439-469. [CrossRef] [PubMed]

6. Chen, X.; Varki, A. Advances in the biology and chemistry of sialic acids. ACS Chem. Biol. 2010, 5, 163-176. [CrossRef] [PubMed]

7. Schauer, R.; Srinivasan, G.V.; Wipfler, D.; Kniep, B.; Schwartz-Albiez, R. O-Acetylated Sialic Acids and Their Role in Immune Defense. In The Molecular Immunology of Complex Carbohydrates-3. Advances in Experimental Medicine and Biology; Wu, A., Ed.; Springer: Boston, MA, USA, 2011; Volume 705, pp. 525-548. [CrossRef]

8. Schauer, R. Achievements and challenges of sialic acid research. Glycoconj. J. 2000, 17, 485-499. [CrossRef]

9. Kooner, A.S.; Yu, H.; Chen, X. Synthesis of N-glycolylneuraminic acid (Neu5Gc) and its glycosides. Front. Immunol. 2019, 10. [CrossRef]

10. Varki, A. Loss of N-glycolylneuraminic acid in humans: Mechanisms, consequences, and implications for hominid evolution. Am. J. Phys. Anthropol. 2001, 116, 54-69. [CrossRef]

11. Kawano, T.; Koyama, S.; Takematsu, H.; Kozutsumi, Y.; Kawasaki, H.; Kawashima, S.; Kawasaki, T.; Suzuki, A. Molecular cloning of cytidine monophospho- $N$-acetylneuraminic acid hydroxylase. Regulation of speciesand tissue-specific expression of $\mathrm{N}$-glycolylneuraminic acid. J. Biol. Chem. 1995, 270, 16458-16463. [CrossRef]

12. Shaw, L.; Schneckenburger, P.; Carlsen, J.; Christiansen, K.; Schauer, R. Mouse liver cytidine-5'monophosphate- $\mathrm{N}$-acetylneuraminic acid hydroxylase. Eur. J. Biochem. 1992, 206, 269-277. [CrossRef]

13. Samraj, A.; Läubli, H.; Varki, N.; Varki, A. Involvement of a non-human sialic acid in human cancer. Front. Oncol. 2014, 4. [CrossRef]

14. Kozutsumi, Y.; Kawano, T.; Kawasaki, H.; Suzuki, K.; Yamakawa, T.; Suzuki, A. Reconstitution of CMP-N-acetylneuraminic acid hydroxylation activity using a mouse liver cytosol fraction and soluble cytochrome b5 purified from horse erythrocytes. J. Biochem. 1991, 110, 429-435. [CrossRef]

15. Rota, P.; Cirillo, F.; Piccoli, M.; Gregorio, A.; Tettamanti, G.; Allevi, P.; Anastasia, L. Synthesis and biological evaluation of several dephosphonated analogues of CMP-Neu5Ac as inhibitors of GM3-synthase. Chem. Eur. J. 2015, 21, 14614-14629. [CrossRef]

16. Derevitskaya, V.A.; Kalinevich, V.M.; Kochetkov, N.K. Lactone of N-acetylneuraminic acid. Dokl. Akad. Nauk SSSR 1966, 169, 1087-1090.

17. Colombo, R.; Anastasia, M.; Rota, P.; Allevi, P. The first synthesis of N-acetylneuraminic acid 1,7-lactone. Chem. Commun. 2008, 43, 5517-5519. [CrossRef]

18. Allevi, P.; Anastasia, M.; Costa, M.L.; Rota, P. Two procedures for the syntheses of labeled sialic acids and their 1,7-lactones. Tetrahedron Asymmetry 2011, 22, 338-344. [CrossRef]

19. Allevi, P.; Rota, P.; Scaringi, R.; Colombo, R.; Anastasia, M. Chemoselective synthesis of sialic acid 1,7-lactones. J. Org. Chem. 2010, 75, 5542-5548. [CrossRef] [PubMed]

20. Colombo, R.; Anastasia, M.; Rota, P.; Allevi, P. Correction: The first synthesis of $N$-acetylneuraminic acid 1,7-lactone. Chem. Commun. 2015, 51, 4719. [CrossRef] [PubMed]

21. Allevi, P.; Rota, P.; Scaringi, R.; Colombo, R.; Anastasia, M. Correction to "chemoselective synthesis of sialic acid 1,7-lactones". J. Org. Chem. 2015, 80, 3357. [CrossRef] [PubMed]

22. Mitsuoka, C.; Ohmori, K.; Kimura, N.; Kanamori, A.; Komba, S.; Ishida, H.; Kiso, M.; Kannagi, R. Regulation of selectin binding activity by cyclization of sialic acid moiety of carbohydrate ligands on human leukocytes. Proc. Natl. Acad. Sci. USA 1999, 96, 1597-1602. [CrossRef]

23. Tanaka, H.; Ando, H.; Ishida, H.; Kiso, M.; Ishihara, H.; Koketsu, M. Synthetic study on $\alpha(2 \rightarrow 8)$-linked oligosialic acid employing 1,5-lactamization as a key step. Tetrahedron Lett. 2009, 50, 4478-4481. [CrossRef]

24. Hamada, T.; Hirota, H.; Yokoyama, S.; Otsubo, N.; Ishida, H.; Kiso, M.; Kanamori, A.; Kannagi, R. NMR analysis of novel ganglioside GM4 analogues containing de- $\mathrm{N}$-acetyl and lactamized sialic acid: Probes for searching new ligand structures for human L-selectin. Magn. Reson. Chem. 2002, 40, 517-523. [CrossRef]

25. Ando, H.; Koike, Y.; Koizumi, S.; Ishida, H.; Kiso, M. 1,5-lactamized sialyl acceptors for various disialoside syntheses: Novel method for the synthesis of glycan portions of Hp-s6 and HLG-2 gangliosides. Angew. Chem. Int. Ed. Engl. 2005, 44, 6759-6763. [CrossRef] [PubMed]

26. Li, Y.F.; Maliakel, B.P.; Zbiral, E. Formation of a lactam derivative on direct benzylation of $N$-acetylneuraminic acid alpha-methyl ketoside. Synlett 1992, 7, 561-562. [CrossRef]

27. Meindl, P.; Bodo, G.; Palese, P.; Schulman, J.; Tuppy, H. Inhibition of neuraminidase activity by derivatives of 2-deoxy-2,3-dehydro-N-acetylneuraminic acid. Virology 1974, 58, 457-463. [CrossRef] 
28. Meindl, P.; Tuppy, H. 2-deoxy-2.3-dehydro-Sialic Acids. I. synthesis and properties of 2-deoxy-2.3-dehydro$\mathrm{N}$-acyl-neuraminic acids and their methyl esters. Mon. Chem. 1969, 100, 1295-1306. [CrossRef]

29. Rota, P.; La Rocca, P.; Piccoli, M.; Montefiori, M.; Cirillo, F.; Olsen, L.; Orioli, M.; Allevi, P.; Anastasia, L. Potent inhibitors against newcastle disease virus hemagglutinin-neuraminidase. ChemMedChem 2018, 13, 236-240. [CrossRef] [PubMed]

30. Rota, P.; La Rocca, P.; Cirillo, F.; Piccoli, M.; Allevi, P.; Anastasia, L. The acidic hydrolysis of N-acetylneuraminic 4,5-oxazoline allows a direct functionalization of the C5 position of Neu5Ac2en (DANA). RSC Adv. 2020, 10, 162-165. [CrossRef]

31. Rota, P.; Papini, N.; La Rocca, P.; Montefiori, M.; Cirillo, F.; Piccoli, M.; Scurati, R.; Olsen, L.; Allevi, P.; Anastasia, L. Synthesis and chemical characterization of several perfluorinated sialic acid glycals and evaluation of their in vitro antiviral activity against Newcastle disease virus. MedChemComm 2017, 8, 1505-1513. [CrossRef]

32. Allevi, P.; Rota, P.; Agnolin, I.S.; Gregorio, A.; Anastasia, M. A Simple synthetic access to differently 4-substituted Neu5Ac2en glycals combining elements of molecules with anti-neuraminidase activity. Eur. J. Org. Chem. 2013, 2013, 4065-4077. [CrossRef]

33. Rota, P.; Allevi, P.; Agnolin, I.S.; Mattina, R.; Papini, N.; Anastasia, M. A simple synthesis of $N$-perfluoroacylated and $N$-acylated glycals of neuraminic acid with a cyclic aminic substituent at the 4alpha position as possible inhibitors of sialidases. Org. Biomol. Chem. 2012, 10, 2885-2894. [CrossRef] [PubMed]

34. Agnolin, I.S.; Rota, P.; Allevi, P.; Gregorio, A.; Anastasia, M. Simple and rapid procedures for the synthesis of 5-acylated $4 \beta$-acylamido- and 4 $\beta$-acetoxyneuraminic acid glycals. Eur. J. Org. Chem. 2012, 2012, 6537-6547. [CrossRef]

35. Rota, P.; Agnolin, I.S.; Allevi, P.; Anastasia, M. Facile diastereoselective entry to $4 \beta$-acylamidation of Neu5Ac2en glycals using their N-perfluoroacylated congeners as key tools. Eur. J. Org. Chem. 2012, 2012, 2508-2510. [CrossRef]

36. Cheng, M.-C.; Lin, C.-H.; Lin, H.-J.; Yu, Y.-P.; Wu, S.-H. Hydrolysis, lactonization, and identification of $\alpha(2 \rightarrow 8) / \alpha(2 \rightarrow 9)$ alternatively linked tri-, tetra-, and polysialic acids. Glycobiology 2004, 14, 147-155. [CrossRef]

37. Lifely, M.R.; Gilbert, A.S.; Moreno, C. Rate, mechanism, and immunochemical studies of lactonisation in serogroup B and C polysaccharides of Neisseria meningitidis. Carbohydr. Res. 1984, 134, 229-243. [CrossRef]

38. Lifely, M.R.; Gilbert, A.S.; Moreno, C. Sialic acid polysaccharide antigens of Neisseria meningitidis and Escherichia coli: Esterification between adjacent residues. Carbohydr. Res. 1981, 94, 193-203. [CrossRef]

39. Ando, S.; Yu, R.K.; Scarsdale, J.N.; Kusunoki, S.; Prestegard, J.H. High resolution proton NMR studies of gangliosides. Structure of two types of GD3 lactones and their reactivity with monoclonal antibody R24. J. Biol. Chem. 1989, 264, 3478-3483.

40. Kielczynski, W.; Bartholomeusz, R.K.; Harrison, L. Characterization of ganglioside associated with the thyrotrophin receptor. Glycobiology 1994, 4, 791-796. [CrossRef]

41. Fronza, G.; Kirschner, G.; Acquotti, D.; Sonnino, S. Synthesis, structure, and conformation of the dilactone derivative of Gd1b ganglioside. Carbohydr. Res. 1989, 195, 51-58. [CrossRef]

42. Maggio, B.; Ariga, T.; Yu, R.K. Ganglioside GD3 lactones: Polar head group mediated control of the intermolecular organization. Biochemistry 1990, 29, 8729-8734. [CrossRef]

43. Yu, R.K.; Koerner, T.A.W.; Ando, S.; Yohe, H.C.; Prestegard, J.H. High-resolution proton NMR studies of gangliosides. III. Elucidation of the structure of ganglioside GM3 lactone. J. Biochem. 1985, 98, 1367-1373. [CrossRef] [PubMed]

44. Terabayashi, T.; Kawanishi, Y. Naturally occurring ganglioside lactones in Minke whale brain. Carbohydr. Res. 1998, 307, 281-290. [CrossRef]

45. Terabayashi, T.; Ogawa, T.; Kawanishi, Y. Characterization of Ganglioside GM4 Lactones isolated from the whale brain. J. Biochem. 1990, 107, 868-871. [CrossRef]

46. Sato, T.; Ishii, M.; Ohtake, F.; Nagata, K.; Terabayashi, T.; Kawanishi, Y.; Okahata, Y. Binding affinity of GM3 lactone for influenza virus. Glycoconj. J. 1999, 16, 223-227. [CrossRef]

47. Cheng, M.-C.; Lin, C.-H.; Wang, H.-Y.; Lin, H.-R.; Wu, S.-H. Regioselective lactonization of tetrasialic acid. Angew. Chem. Int. Ed. Engl. 2000, 39, 772-776. [CrossRef] 
48. Yu, Y.-P.; Cheng, M.-C.; Lin, H.-R.; Lin, C.-H.; Wu, S.-H. Acid-catalyzed hydrolysis and lactonization of $\alpha 2,8$-linked oligosialic acids. J. Org. Chem. 2001, 66, 5248-5251. [CrossRef]

49. Bratosin, D.; Palii, C.; Moicean, A.D.; Zanetta, J.-P.; Montreuil, J. Reduced diversity of the human erythrocyte membrane sialic acids in polycythemia vera. Absence of $N$-glycolylneuraminic acid and characterisation of $\mathrm{N}$-acetylneuraminic acid 1,7 lactone. Biochimie 2007, 89, 355-359. [CrossRef] [PubMed]

50. Rinninger, A.; Richet, C.; Pons, A.; Kohla, G.; Schauer, R.; Bauer, H.C.; Zanetta, J.-P.; Vlasak, R. Localisation and distribution of $\mathrm{O}$-acetylated $\mathrm{N}$-acetylneuraminic acids, the endogenous substrates of the hemagglutinin-esterases of murine coronaviruses, in mouse tissue. Glycoconj. J. 2006, 23, 73-84. [CrossRef] [PubMed]

51. Zanetta, J.-P.; Srinivasan, V.; Schauer, R. Analysis of monosaccharides, fatty constituents and rare O-acetylated sialic acids from gonads of the starfish Asterias rubens. Biochimie 2006, 88, 171-178. [CrossRef]

52. Bohin, A.; Bouchart, F.; Richet, C.; Kol, O.; Leroy, Y.; Timmerman, P.; Huet, G.; Bohin, J.-P.; Zanetta, J.-P. GC/MS identification and quantification of constituents of bacterial lipids and glycoconjugates obtained after methanolysis as heptafluorobutyrate derivatives. Anal. Biochem. 2005, 340, 231-244. [CrossRef]

53. Pons, A.; Richet, C.; Robbe, C.; Herrmann, A.; Timmerman, P.; Huet, G.; Leroy, Y.; Carlstedt, I.; Capon, C.; Zanetta, J.-P. Sequential GC/MS Analysis of sialic acids, monosaccharides, and amino acids of glycoproteins on a single sample as heptafluorobutyrate derivatives. Biochemistry 2003, 42, 8342-8353. [CrossRef] [PubMed]

54. Bulai, T.; Bratosin, D.; Pons, A.; Montreuil, J.; Zanetta, J.-P. Diversity of the human erythrocyte membrane sialic acids in relation with blood groups. FEBS Lett. 2003, 534, 185-189. [CrossRef]

55. Robbe, C.; Capon, C.; Maes, E.; Rousset, M.; Zweibaum, A.; Zanetta, J.-P.; Michalski, J.C. Evidence of regio-specific glycosylation in human intestinal mucins: Presence of an acidic gradient along the intestinal tract. J. Biol. Chem. 2003, 278, 46337-46348. [CrossRef] [PubMed]

56. Cebo, C.; Vergoten, G.; Zanetta, J.-P. Lectin activities of cytokines: Functions and putative carbohydrate-recognition domains. Biochim. Biophys. Acta 2002, 1572, 422-434. [CrossRef]

57. Pons, A.; Timmerman, P.; Leroy, Y.; Zanetta, J.-P. Gas-chromatography/mass-spectrometry analysis of human skin constituents as heptafluorobutyrate derivatives with special reference to long-chain bases. J. Lipid Res. 2002, 43, 794-804.

58. Zanetta, J.-P.; Cebo, C.; Vergoten, G. Lectin activities of cytokines: A new concept in immunology. Trends Glycosci. Glycotechnol. 2002, 14, 303-318. [CrossRef]

59. Cebo, C.; Dambrouck, T.; Maes, E.; Laden, C.; Strecker, G.; Michalski, J.C.; Zanetta, J.-P. Recombinant human interleukins IL-1alpha, IL-1beta, IL-4, IL-6, and IL-7 show different and specific calcium-independent carbohydrate-binding properties. J. Biol. Chem. 2001, 276, 5685-5691. [CrossRef]

60. Zanetta, J.-P.; Pons, A.; Iwersen, M.; Mariller, C.; Leroy, Y.; Timmerman, P.; Schauer, R. Diversity of sialic acids revealed using gas chromatography/mass spectrometry of heptafluorobutyrate derivatives. Glycobiology 2001, 11, 663-676. [CrossRef]

61. Pons, A.; Popa, J.; Portoukalian, J.; Bodennec, J.; Ardail, D.; Kol, O.; Martin-Martin, M.J.; Hueso, P.; Timmerman, P.; Leroy, Y.; et al. Single-step gas chromatography-mass spectrometry analysis of glycolipid constituents as heptafluorobutyrate derivatives with a special reference to the lipid portion. Anal. Biochem. 2000, 284, 201-216. [CrossRef]

62. Zanetta, J.P.; Timmerman, P.; Leroy, Y. Gas-liquid chromatography of the heptafluorobutyrate derivatives of the O-methyl-glycosides on capillary columns: A method for the quantitative determination of the monosaccharide composition of glycoproteins and glycolipids. Glycobiology 1999, 9, 255-266. [CrossRef]

63. Horne, C.R.; Kind, L.; Davies, J.S.; Dobson, R.C.J. On the structure and function of escherichia coli YjhC: An oxidoreductase involved in bacterial sialic acid metabolism. Proteins 2020, 88, 654-668. [CrossRef] [PubMed]

64. Vimr, E.R. Unified theory of bacterial sialometabolism: How and why bacteria metabolize host sialic acids. ISRN Microbiol. 2013, 2013, 816713. [CrossRef] [PubMed]

65. Popa, I.; Zanetta, J.P.; Portoukalian, J.; Thomas, L. GM3 ganglioside of human melanoma tumors contains a lactonized sialic that is a ligand of interleukin-4. J. Investig. Dermatol. 2002, 118, 903.

66. Rota, P.; Anastasia, L.; Allevi, P. Elucidation of several neglected reactions in the GC-MS identification of sialic acids as heptafluorobutyrates calls for an urgent reassessment of previous claims. Org. Biomol. Chem. 2015, 13, 4931-4939. [CrossRef] [PubMed] 
67. Gervay, J.; Ramamoorthy, P.S.; Mamuya, N.N. Ring opening of sialyllactones with glycine esters: Synthesis of selectively protected glycinyl-NeuAc saccharopeptides. Tetrahedron 1997, 53, 11039-11048. [CrossRef]

68. Gervay, J.; Mamuya, N.N.; Andrew Barber, R. Synthesis of ${ }^{13} \mathrm{C}$ enriched sialyllactones and their characterization using isotope edited inverse detected NMR spectroscopy. Tetrahedron Lett. 1997, 38, 1865-1868. [CrossRef]

69. Parrill, A.L.; Mamuya, N.; Dolata, D.P.; Gervay, J. Computational studies of sialyllactones: Methods and uses. Glycoconj. J. 1997, 14, 523-529. [CrossRef]

70. Sato, S.; Furuhata, K.; Ogura, H. Studies on Sialic Acids.XIV. Lactone derivatives of N-acetylneuraminic acid. Chem. Pharm. Bull. 1988, 36, 4678-4688. [CrossRef]

71. Sugiyama, N.; Sugai, K.E.I.; Yamada, N.; Goto, M.; Ban, C.; Furuhata, K.; Takayanagi, H.; Ogura, H. Studies on Sialic Acids. IX: Formation of a 1,7-lactone derivative by direct acetylation of $N$-acetylneuraminic acid. Chem. Pharm. Bull. 1988, 36, 1147-1152. [CrossRef]

72. Kirchner, E.; Thiem, F.; Dernick, R.; Heukeshoven, J.; Thieina, J. Studies on the glycosylation of $\mathrm{N}$-acetylneuraminic acid. J. Carbohydr. Chem. 1988, 7, 453-486. [CrossRef]

73. Khorlin, A.Y.; Privalova, I.M. Acylation of N-acetylneuraminic acid. Chem. Nat. Compd. 1967, 3, $159-162$. [CrossRef]

74. Horn, E.J.; Saludes, J.P.; Gervay-Hague, J. Investigation into an efficient synthesis of 2,3-dehydro- $N$-acetyl neuraminic acid leads to three decarboxylated sialic acid dimers. Carbohydr. Res. 2008, 343, 936-940. [CrossRef]

75. Tsvetkov, Y.E.; Schmidt, R.R. 8-O-Sialylation of derivatives of neuraminic acid 1,7-lactone unusual stereoselectivity. Tetrahedron Lett. 1994, 35, 8583-8586. [CrossRef]

76. La Rocca, P.; Rota, P.; Piccoli, M.; Cirillo, F.; Orioli, M.; Ravelli, A.; Allevi, P.; Anastasia, L. Lactonization method to assign the anomeric configuration of the 3,4-unsaturated congeners of $N$-acetylneuraminic acid. J. Org. Chem. 2019, 84, 5460-5470. [CrossRef]

77. Compound 4a (N-Acetyl-beta-neuraminic Acid 1,7-Lactone CAS: 335592-15-9) Is Commercially Available from Atomax Chemicals. Available online: http://en.atomaxchem.com (accessed on 29 October 2020).

78. Rota, P.; Allevi, P.; Anastasia, L. The sialic acids waltz: Novel stereoselective isomerization of the 1,7-lactones of $\mathrm{N}$-acetylneuraminic acids into the corresponding $\gamma$-lactones and back to the free sialic acids. Asian J. Org. Chem. 2015, 4, 1315-1321. [CrossRef]

79. Nakamura, M.; Takayanagi, H.; Furuhata, K.; Ogura, H. synthesis and characterization of furanose and pyranose derivatives of 3-deoxy-D-glycero-D-galacto-2-nonulosonic acid (KDN). Chem. Pharm. Bull. 1992, 40, 879-885. [CrossRef]

80. David, S.; Malleron, A.; Cavayé, B. Some derivatives of 3-deoxy-D-glycero-D-galacto-non-2-ulosonic acid (KDN). Carbohydr. Res. 1994, 260, 233-241. [CrossRef]

81. Kuhn, R.; Baschang, G. Die konfiguration der sialinsäuren am C-atom 4. Chem. Ber. 1962, 95, $2384-2385$. [CrossRef]

82. Kuhn, R.; Brossmer, R. The configuration of sialic acids. Angew. Chem. Int. Ed. 1962, 1, 218. [CrossRef]

83. Kuhn, R.; Baschang, G. Aminozucker-Synthesen, XXV. Synthese der lactaminsäure. Justus Liebigs Ann. Chem. 1962, 659, 156-163. [CrossRef]

84. Faillard, H.; Blohm, M. Synthesis of N-glycolyneuraminic acid. Hoppe Seyler Z. Physiol. Chem. 1965, 341, 167-171. [CrossRef] [PubMed]

85. Sawada, Y.; Nakatsuka, S. Synthesis of gamma-lactone-type sialic acid, an isomer of 2,3-dehydrosialic acid. Biosci. Biotechnol. Biochem. 2010, 74, 1106-1107. [CrossRef] [PubMed]

86. Khorlin, A.Y.; Privalova, I.M. Synthesis of N-acetylneuraminic acid 8-methyl ether. Carbohydr. Res. 1970, 13, 373-377. [CrossRef]

87. Holmquist, L. 7,9-O-ethylidene and 7,9-O-benzylidene derivatives of 5-acetamido-3,5-dideoxy-Dglycero-D-galacto-nonulosonic acid (N-acetylneuraminic acid). Acta Chem. Scand. 1971, 25, 712-716. [CrossRef] [PubMed]

88. Zbiral, E.; Schmid, W. Structural modifications on $N$-acetylneuraminic Acid. 4. Transformations on the diethyldithioketal of $\mathrm{N}$-acetylneuraminic acid-gamma-lactone. Mon. Chem. 1985, 116, 253-262. [CrossRef]

89. Furuhata, K.; Sato, S.; Anazawa, K.; Goto, M.; Takayanagi, H.; Ogura, H. Studies on sialic acids. VIII. The 1,4-lactone derivatives of $N$-acetylneuraminic acid. Chem. Pharm. Bull. 1987, 35, 3609-3614. [CrossRef] 
90. Warwel, M.; Fessner, W.-D. Indium-mediated chain-extension: An improved protocol for the concise, diastereospecific synthesis of KDN and other sialic acids. Synlett 2000, 2000, 865-867. [CrossRef]

91. Rota, P.; Allevi, P.; Costa, M.L.; Anastasia, M. High yielding N-transacylation of secondary amides in acids labile molecules by the action of perfluorinated anhydrides in the presence of a mild base. Tetrahedron Asymmetry 2010, 21, 2681-2686. [CrossRef]

92. Rota, P.; Allevi, P.; Mattina, R.; Anastasia, M. Reaction of N-acetylneuraminic acid derivatives with perfluorinated anhydrides: A short access to $N$-perfluoracylated glycals with antiviral properties. Org. Biomol. Chem. 2010, 8, 3771-3776. [CrossRef]

93. Monticelli, E.; Aman, C.S.; Costa, M.L.; Rota, P.; Bogdan, D.; Allevi, P.; Cighetti, G. Simultaneous free and glycosylated pyridinium crosslink determination in urine: Validation of an HPLC-fluorescence method using a deoxypyridinoline homologue as internal standard. J. Chromatogr. B Anal. Technol. Biomed. Life Sci. 2011, 879, 2764-2771. [CrossRef] [PubMed]

94. Rota, P.; Allevi, P.; Colombo, R.; Costa, M.L.; Anastasia, M. General and chemoselective N-transacylation of secondary amides by means of perfluorinated anhydrides. Angew. Chem. Int. Ed. 2010, 49, 1850-1853. [CrossRef] [PubMed]

Publisher's Note: MDPI stays neutral with regard to jurisdictional claims in published maps and institutional affiliations.

(C) 2020 by the authors. Licensee MDPI, Basel, Switzerland. This article is an open access article distributed under the terms and conditions of the Creative Commons Attribution (CC BY) license (http://creativecommons.org/licenses/by/4.0/). 